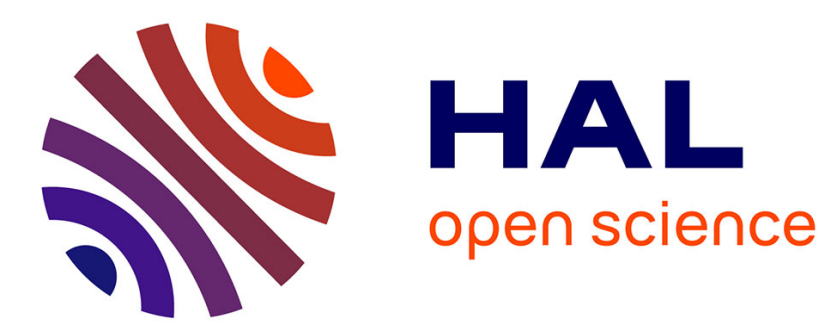

\title{
The Actomyosin Systems in Apicomplexa
}

Karine Frénal, Aarti Krishnan, Dominique Soldati-Favre

\section{To cite this version:}

Karine Frénal, Aarti Krishnan, Dominique Soldati-Favre. The Actomyosin Systems in Apicomplexa. Myosins, A Superfamily of Molecular Motors, pp.331-354, 2020, 10.1007/978-3-030-38062-5_14 . hal03040507

\section{HAL Id: hal-03040507 https://hal.science/hal-03040507}

Submitted on 6 Oct 2021

HAL is a multi-disciplinary open access archive for the deposit and dissemination of scientific research documents, whether they are published or not. The documents may come from teaching and research institutions in France or abroad, or from public or private research centers.
L'archive ouverte pluridisciplinaire HAL, est destinée au dépôt et à la diffusion de documents scientifiques de niveau recherche, publiés ou non, émanant des établissements d'enseignement et de recherche français ou étrangers, des laboratoires publics ou privés. 


\title{
The Actomyosin Systems in Apicomplexa
}

\author{
Karine Frénal, Aarti Krishnan, \\ and Dominique Soldati-Favre
}

\begin{abstract}
The phylum of Apicomplexa groups obligate intracellular parasites that exhibit unique classes of unconventional myosin motors. These parasites also encode a limited repertoire of actins, actin-like proteins, actinbinding proteins and nucleators of filamentous actin (F-actin) that display atypical properties. In the last decade, significant progress has been made to visualize F-actin and to unravel the functional contribution of actomyosin systems in the biology of Toxoplasma and Plasmodium, the most genetically-tractable members of the phylum. In addition to assigning specific roles to each myosin, recent biochemical and structural studies have begun to uncover mechanistic insights into myosin function at the atomic level. In several
\end{abstract}

K. Frénal $(\bowtie)$

Microbiologie Fondamentale et Pathogénicité, UMR

5234, University of Bordeaux and CNRS,

Bordeaux Cedex, France

Department of Microbiology and Molecular

Medicine, Faculty of Medicine, University of

Geneva, Geneva, Switzerland

e-mail: karine.frenal@u-bordeaux.fr

\footnotetext{
A. Krishnan - D. Soldati-Favre

Department of Microbiology and Molecular

Medicine, Faculty of Medicine, University of

Geneva, Geneva, Switzerland

e-mail: aarti.krishnan@unige.ch; dominique.

soldati-favre@unige.ch
}

instances, the myosin light chains associated with the myosin heavy chains have been identified, helping to understand the composition of the motor complexes and their mode of regulation. Moreover, the considerable advance in proteomic methodologies and especially in assignment of posttranslational modifications is offering a new dimension to our understanding of the regulation of actin dynamics and myosin function. Remarkably, the actomyosin system contributes to three major processes in Toxoplasma gondii: (i) organelle trafficking, positioning and inheritance, (ii) basal pole constriction and intravacuolar cell-cell communication and (iii) motility, invasion, and egress from infected cells. In this chapter, we summarize how the actomyosin system harnesses these key events to ensure successful completion of the parasite life cycle.

\section{Keywords}

Toxoplasma $\cdot$ Plasmodium $\cdot$ Actomyosin system · Motility · Invasion · Organelle inheritance $\cdot$ Basal pole constriction . Cell-cell communication 


\subsection{Introduction}

\subsubsection{The Phylum of Apicomplexa}

The phylum Apicomplexa is composed of obligate intracellular parasites and comprises several pathogens of medical and veterinary significance such as Plasmodium, responsible for malaria, Toxoplasma, the agent of opportunistic toxoplasmosis, or Cryptosporidium, responsible for the diarrheal cryptosporidiosis. Apicomplexans are single-celled eukaryotes of the infrakingdom Alveolate, which also includes ciliates and dinoflagellate algae (Gould et al. 2008). Although these protists are very diverse in their shape and lifestyle, they are unified by a common structural feature: the presence of a pellicle composed of the external plasma membrane (PM) under which lies membranous sacs termed alveoli or inner membrane complex (IMC) (Fig. 14.1a). On the cytoplasmic face of the IMC, a meshwork of intermediate filament-like proteins connects the pellicle to the cortical microtubules that constitute the cytoskeleton of the parasite (Harding and Meissner 2014). Most Apicomplexans possess a non-photosynthetic relic plastid named the "apicoplast" that originates from secondary endosymbiosis of a red alga (van Dooren and Striepen 2013) (Fig. 14.1a). This organelle fulfils metabolic functions that are critical for parasite survival. Apicomplexans are further characterized by the presence of an apical complex composed of cytoskeletal elements, the apical polar rings, and two sets of secretory organelles, the micronemes and rhoptries, which play a critical role in gliding motility and during the invasion process and egress from infected cells (Hu et al. 2006; Frénal et al. 2017a). In the subclass of Coccidia, which comprises, among others, Toxoplasma gondii, Eimeria, and Cryptosporidium species, the conoid and the pre-conoidal ring are additional cytoskeletal elements of the apical complex (Fig. 14.1a). The conoid is an organelle found at the apex of these parasites and composed of $\alpha$-tubulin-rich spiraling fibers named conoid fibers (Hu et al. 2002). The conoid is retracted in intracellular parasites and protrudes beyond the IMC in extracellular parasites upon an increase in intracellular calcium, although its function remains unknown (Monteiro et al. 2001).

In this chapter, we will focus on the two most studied and tractable parasites of the phylum, Toxoplasma and Plasmodium. Studies on T. gondii are mainly carried out on the fast-replicative stage, the tachyzoite, whose lytic cycle is depicted in Fig. 14.1b. Studies on human malaria parasite P. falciparum predominantly focus on erythrocytic stages, whereas $P$. berghei, a rodent model of malaria offers the possibility to investigate the full life cycle of the parasite taking place between the murine intermediate host and the Anopheles mosquito vector, the definitive host (Fig. 14.1c).

\subsubsection{Parasite Lifestyle}

The apicomplexan motile stages, also called zoites, exhibit a unique form of substratedependent locomotion. In contrast to other protozoans, they do not rely on specific attributes such as flagella or amoeboid movement. Instead, they use gliding motility powered by an actomyosin system, termed glideosome, to actively penetrate into their host cell (invasion), exit from the infected cell (egress), and cross biological barriers. This molecular machine is located within the pellicle in the space between the plasma membrane and the IMC (Frénal et al. 2017a). Following an increase in intracellular calcium, exocytosis of microneme content occurs at the apical pole of the parasite leading to the insertion of micronemal adhesins into the parasite plasma membrane. During motility, these adhesins can bind to host receptors at the surface of target cells and the rearward translocation of these adhesinreceptor complexes by the glideosome propels the parasite forward. During invasion, apical microneme secretion induces the reorientation of the parasite, placing the apex of the parasite in juxtaposition with the host cell plasma membrane (Fig. 14.1b). Subsequently, rhoptry discharge occurs, releasing rhoptry neck (RONs) and rhoptry bulb proteins (ROPs) into the host cells. A complex of RONs (RON2/4/5) inserted within the host cell plasma membrane and inter- 
a

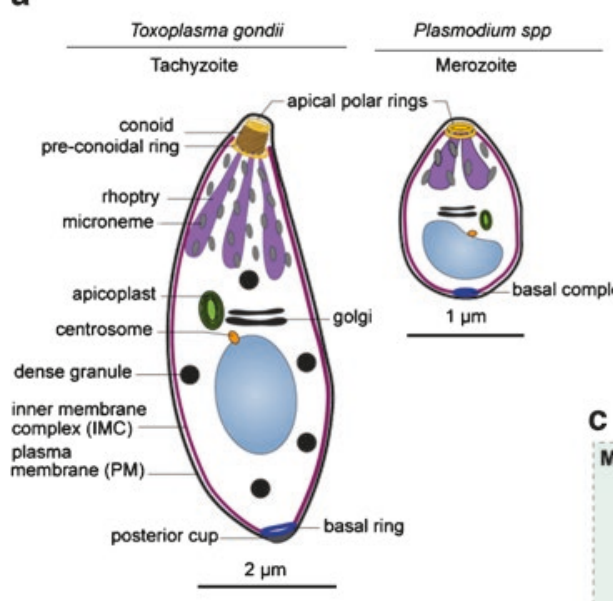

b
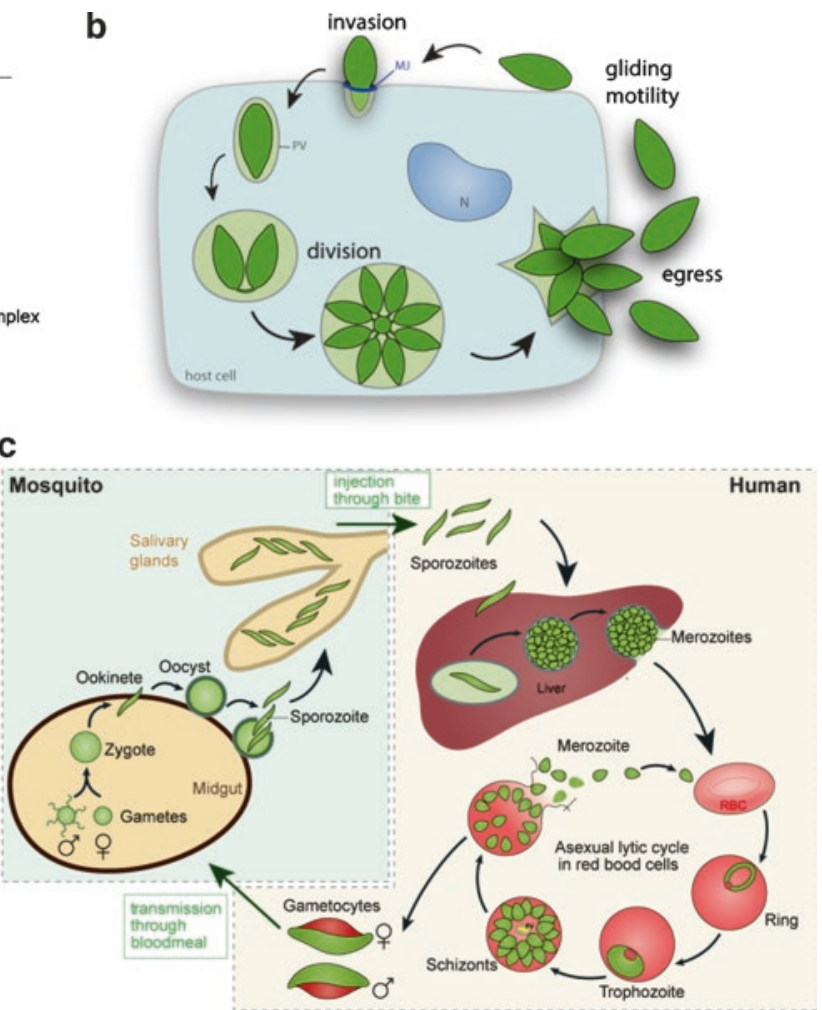

Fig. 14.1 Example of zoites in Toxoplasma gondii and Plasmodium species and their life cycle. (a) Schematic representation of Toxoplasma gondii tachyzoite (left panel), a member of the coccidian sub-group of Apicomplexa and Plasmodium merozoite, belonging to the haemosporida sub-group (right panel). The main difference resides in the presence of the conoid, a structure composed of tubulin, located at the apex of the Coccidians. The zoites harbor three types of secretory organelles, the micronemes, rhoptries, and dense granules and a nonphotosynthetic plastic-like organelle, the apicoplast. Mitochondrion and endoplasmic reticulum are not represented but are present in these zoites. (b) Lytic cycle of Toxoplasma gondii. The fast replicative tachyzoite is capable of entering virtually any nucleated cell. Within the host cell, the parasite divides by endodyogeny within a parasitophorous vacuole and after several rounds of replication, will eventually egress from the infected cell, lysing it, and glide to invade a neighboring cell. $N$ nucleus, $P V$ parasitophorous vacuole, $M J$ moving junction. (c). Life cycle of
Plasmodium falciparum taking place between the definitive host, the Anopheles mosquito, and the intermediate host, the human. Infection of the human starts through the bite of an infected female mosquito, which injects sporozoites into the dermis. The sporozoites migrate to the liver and invade hepatocytes where they divide and produce thousands of merozoites that are released into the bloodstream. There, the merozoites infect erythrocytes $(R B C$, red blood cells). The parasites undergo repeated asexual cycles within the RBC, where they progress from rings to trophozoites and schizonts and are eventually released as merozoites. Some parasites will develop into gametocytes, the sexual forms that circulate in the bloodstream, prior to being taken up by the mosquito. The sexual cycle takes place within its midgut, leading to the formation of motile but non-invasive ookinetes, which migrate through the midgut and develop into oocysts in the epithelium. Maturation of the oocyst produce sporozoites that migrate to the salivary glands where they are ready to infect subsequent hosts through the mosquito bite acting with the microneme protein AMA1 (apical membrane antigen 1) at the parasite plasma membrane forms the moving junction that supports the motility-driven progression of the parasite into the target cell (Harvey et al. 2014; Bichet et al.2014). At the same time, the parasite induces the formation of a non-fusogenic parasitophorous vacuole membrane (PVM), which is derived from the invagination of the host-cell plasma membrane (Mordue et al. 1999). Once intracellular, tachyzoites secrete effectors from the secretory organelles named dense granules that ensure 


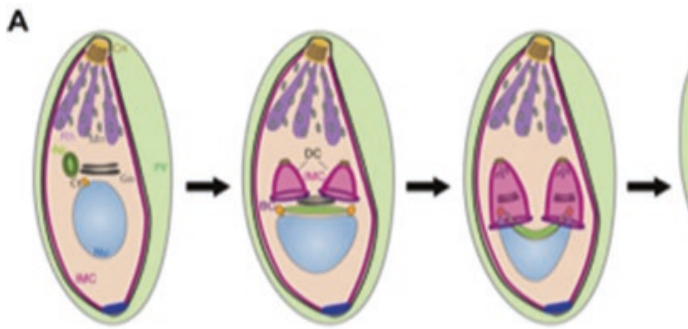

B

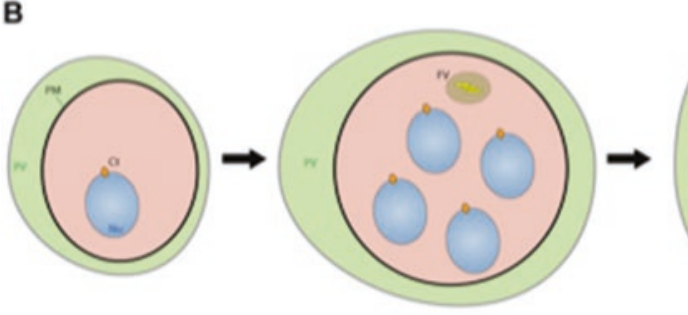

Fig. 14.2 Endodyogeny of Toxoplasma gondii tachyzoite and schizogony of Plasmodium. (a) Scheme of tachyzoites dividing by endodyogeny during which two daughter cells grow inside the mother cell. The scheme highlights particularly the division of the apicoplast that is associated to centrosomes during its inheritance into the daughter cell. The apicoplast is first elongated, then forms a U-shape before being incorporated in the two developing progenies. $C n$ conoid, $R h$ rhoptries, $M n$ micronemes, $\mathrm{Ap}$ apicoplast, $\mathrm{Go}$ Golgi apparatus, $\mathrm{Ct}$ centrosome, $\mathrm{Nu}$

their safe replication by participating in the modification of the parasitophorous vacuole (PV), recruitment of host endoplasmic reticulum and mitochondria, and subversion of host cellular functions (Mercier and Cesbron-Delauw 2015; Hakimi et al. 2017).

Within the PV, T. gondii tachyzoites divide synchronously by endodyogeny, a process during which two daughter cells develop within the mother cell and consume it (Francia and Striepen 2014) (Fig. 14.2a). During this replication, some organelles are made de novo such as the IMC, micronemes, and rhoptries, whereas others, including the mitochondrion and the apicoplast, are inherited (Nishi et al. 2008). For the segregation of the apicoplast, the positioning of the centrosome is crucial since the ends of the apicoplast have been shown to be tightly associated to the centrosomes during its elongation and incorporation into the daughter cells (Striepen et al. 2000).
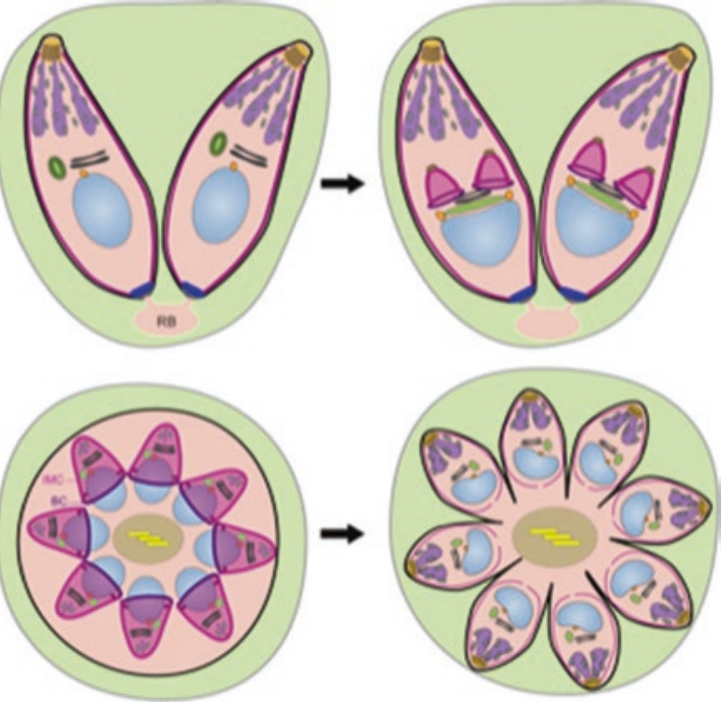

nucleus, $I M C$ inner membrane complex, $B C$ basal complex, $D C$ daughter cells, $P V$ parasitophorous vacuole, $R B$ residual body. (b) Scheme of the schizogony process, the mode of division of Plasmodium species, taking place in the erythrocytes. During this process, the nucleus divides several times and the other organelles are also dividing and/or synthesized de novo. All the organelles are then packaged into the IMC at the same time before the segmentation of the individual merozoites. $P M$ plasma membrane, $P V$ parasitophorous vacuole, $F V$ food vacuole

At each round of division, the basal pole of the parasites constricts and the parasites remain associated through the residual body and adopt an organization in rosettes. After several rounds of replication, the tachyzoites actively egress from the infected cell using the gliding motility and lyse the PVM and host-cell PM through the action of at least one perforin (PLP1) secreted by the micronemes (Kafsack et al. 2009).

In contrast to Toxoplasma, Plasmodium undergoes schizogony in the erythrocytic stage, a process wherein the components of the daughter cells (such as mitochondrion, apicoplast, nucleus, and secretory organelles) are produced in the same cytoplasm before being encapsulated simultaneously within the forming daughter cells (Fig. 14.2b). Cytokinesis then occurs and produces individual invasive merozoites released in the bloodstream that are able to infect new erythrocytes (Francia and Striepen 2014). 
Use of drugs, such as the actin-depolymerizing agent cytochalasin D, revealed that actin does not play a crucial cytoskeletal role during apicomplexan division (Jacot et al. 2013; Frénal et al. 2017b). In contrast, actin polymerization and the connected myosin functions are critical for several steps of the parasite lytic cycle. In the following sections, we will review the role of the actomyosin system for organelle positioning and inheritance, basal complex constriction and intravacuolar cell-cell connection, and gliding motility.

\subsection{Myosin Heavy Chain and Actin Features in Apicomplexa}

\subsubsection{Overview of the Evolution and Classification of Protozoan Myosin Motors}

Myosin motors, one of the largest protein families in eukaryotes, are involved in a multitude of cellular functions. Several comprehensive phylogenetic analyses of myosin heavy chains, progressively updated with newly sequenced genomes, have led to the classification and reconstruction of the evolutionary history of these proteins (Richards and Cavalier-Smith 2005; Foth et al. 2006; Odronitz and Kollmar 2007; SebéPedrós et al. 2014). Foth et al. established the first phylogenetic analysis including myosin sequences from numerous protozoa, such as seven members of Apicomplexa, the ciliate Tetrahymena thermophila as well as five members of the Kinetoplastida phylum (Leishmania and Trypanosoma species), and those from metazoans, fungi, and plants (Foth et al. 2006) (Table 14.1). This analysis led to the discovery of six novel classes of unconventional myosins, three of them restricted to the alveolates (classes XXII, XXIII, XXIV), one of which is found only in trypanosomatids (class XXI). Interestingly, characterization of this broader repertoire of myosin heavy chains identified protein domains, such as FYVE, WW, UBA, ATS1-like and WD40, within the tails that were not previously associated with myosins. In addition, apicomplexan myosins, previously restricted to class XIV, were placed into several classes encompassing myosins from other systematic lineages (classes VI, XXII, XXIII, XXIV), while the class XIV was found to no longer accommodate only apicomplexan myosins but also myosins of $T$. thermophila.

Subsequent phylogenetic analyses have extended and modified the myosin classification described above. Odronitz et al. used 2269 myosin motor domains from 328 organisms to build a new eukaryotic tree of life (Odronitz and Kollmar 2007). This resulted in the definition of 35 myosin classes and some re-classifications. Of relevance concerning the protists, a new class XIII was attributed to myosins specific to the kinetoplastida and exhibiting SH3-like, coiled-coil, and UBA domains, and finally, five new classes were composed solely of apicomplexan myosins.

A more recent study used an expanded taxon sampling in which all major eukaryotic supergroups were represented to define 31 myosin classes (Sebé-Pedrós et al. 2014). With regard to the protozoan myosins, some interesting aspects of this study need to be mentioned. Some alveolate sequences that were previously grouped within myosin class VI (Foth et al. 2006) are now accommodated within myosin class XXIII. Eighteen myosins from the alveolate $T$. thermophila and Paramecium tetraurelia are grouped again within the alveolate-specific myosin class XIV (Sebé-Pedrós et al. 2014), and interestingly, several of them contain the protein domain combination MyTH4/FERM. They constitute the only example of bikonts harboring these domains. Recently, the classification from Foth et al. has been updated to include sequences of two recently sequenced Alveolates, the related photosynthetic chromerids, Chromera velia and Vitrella brassicaformis (Mueller et al. 2017) (Table 14.1). We have chosen to use this latest phylogeny to describe the apicomplexan myosin heavy chains in the following sections. 
Table 14.1 Overview of the repertoire of myosin heavy chains in Apicomplexa

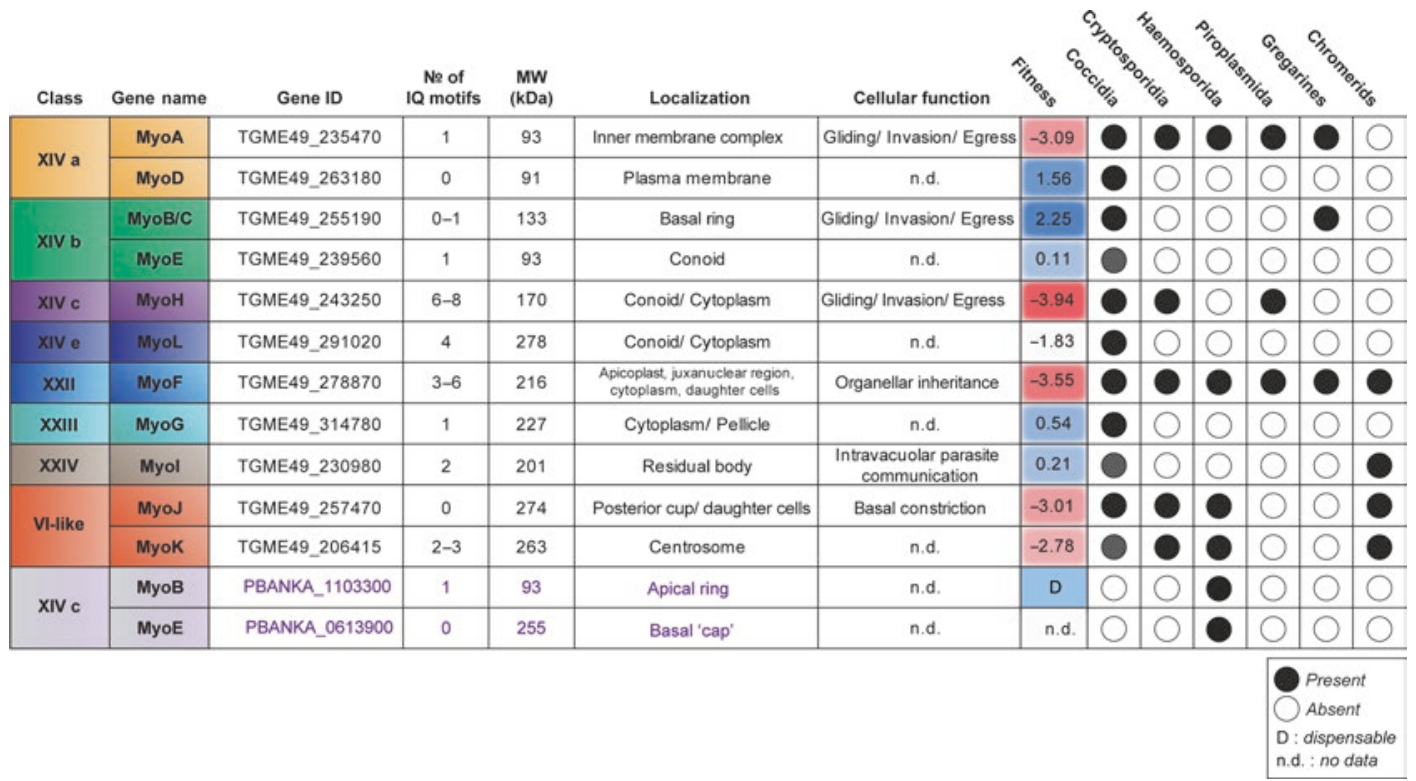

The myosin classification is based on the review from Mueller et al. (2017). The GeneID corresponds to the accession numbers of EuPathDB. The number of IQ motifs has been predicted by SMART (Letunic and Bork 2018). The references for the localization and cellular functions are cited in the text. The fitness scores are from the CRISPR-Cas9 genome wide screen performed on $T$. gondii (Sidik et al. 2016) and the PlasmoGEM database established for the erythrocytic stages of Plasmodium berghei in mice (Bushell et al. 2017). Conservation within the Apicomplexa phylum was performed by a BLAST search. The genes written in purple are specific to Plasmodium species

\subsubsection{Repertoire of Myosin Heavy Chains in Apicomplexa}

Among the apicomplexans, T. gondii has the largest repertoire of myosin heavy chains with 11 isoforms, while $P$. falciparum genome encodes six, two of them, PfMyoB and PfMyoE, being specific to the malaria parasites (Table 14.1). All apicomplexan myosin heavy chains are unconventional and two of them are conserved across the phylum, namely the class XIV MyoA and the class XXVII MyoF, with the latter having also orthologs in the chromerids (Mueller et al. 2017). All the myosin heavy chains have been localized in T. gondii tachyzoites (Fig. 14.3) and P. berghei blood stages and their essentiality evaluated by the generation of knockout, when possible (Wall et al. 2019; Herm-Götz et al. 2006; Andenmatten et al. 2013; Frénal et al. 2014, 2017b), or knockdown (Meissner et al. 2002; Siden-Kiamos et al. 2011; Jacot et al. 2013; Graindorge et al. 2016) cell lines. Out of the 11 myosin heavy chains expressed by the tachyzoite, only two, TgMyoF and $\mathrm{TgMyoH}$, have been completely refractory to deletion and thus are considered indispensable for parasite survival. The other nine motors have been individually deleted with no or very mild impact on tachyzoite fitness, except for TgMyoA. Interestingly, although the class VI-like TgMyoJ and the class XXIV TgMyoI are dispensable for tachyzoite growth in vitro, their deletion uncovered their respective function in basal complex constriction and in intravacuolar parasite connection allowing diffusion of soluble molecules and synchronized division (Frénal et al. 2017b). Deletion of the highly conserved TgMyoA showed a strong defect on the parasite lytic cycle being critical for gliding motility (Andenmatten et al. 2013). However, it was impossible to delete $T g M y o A$ in a background lacking $\mathrm{TgMyoC}$ indicating that these two motors fulfil overlapping functions (Egarter et al. 2014). 


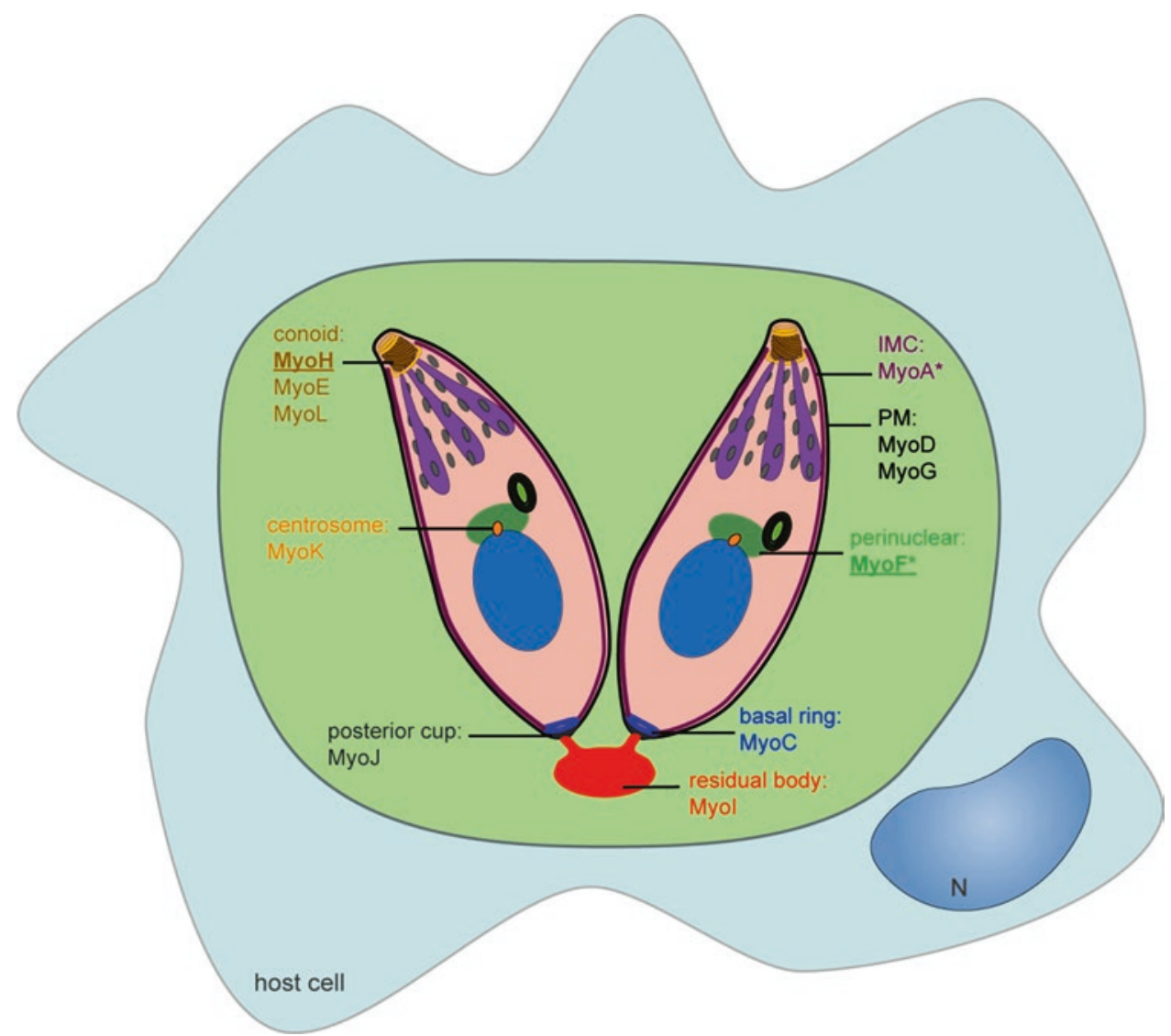

Fig. 14.3 Localization of the Toxoplasma gondii myosins. Scheme of a parasitophorous vacuole containing two tachyzoites connected by the residual body showing the localization of the 11 myosins expressed by this parasite. The dense granule, mitochondria and endoplasmic reticulum are not represented but are present in these zoites. The bold and underlined myosins are the ones found essential for the survival of the tachyzoite. The asterisks indicate the myosins conserved across the Apicomplexa
In Plasmodium species that lack an ortholog of TgMyoC, MyoA is likely essential for all motile stages of the life cycle as is the case for the $P$. berghei ookinete (Siden-Kiamos et al. 2011). Moreover, in $P$. berghei, out of the five other myosin heavy chains, $\mathrm{PbMyoF}$ and $\mathrm{PbMyoK}$ are likely essential for the blood stages since their deletion was unsuccessful (Wall et al. 2019). However, $\mathrm{PbMyoB}, \mathrm{PbMyoE}$, and $\mathrm{PbMyoJ}$ were shown to be dispensable for these asexual stages while the class XIV PbMyoE appeared critical for motility of the mosquito salivary gland sporozoites (Wall et al. 2019).

For Toxoplasma, the experimental results of the individual deletions (Frénal et al. 2017b) are in accordance with the recently-published genome-wide loss-of-function screen performed on $T$. gondii using the CRISPR/Cas9 technology (Sidik et al. 2016), except for the class VI-like TgMyoK, which presents a fitness defect not detected in the phenotyping of the knockout strain (Frénal et al. 2017b) (Table 14.1). Likewise, the fitness data collected for $P$. berghei are in agreement for $\mathrm{PbMyoA}$ and $\mathrm{PbMyoB}$, but a discrepancy exists for $\mathrm{PbMyoK}$, which appears dispensable in the large in vivo genetic screen performed in the mouse model (Bushell et al. 2017) (Table 14.1). The individual role of each myosin heavy chain will be discussed in detail below. 


\subsubsection{Unusual Features of Apicomplexan Actin}

Actin, one of the most abundant and conserved proteins in eukaryotic cells, exists in a monomeric globular state (G-actin) and a polymerized filamentous state (F-actin). It plays fundamental roles in many cellular processes such as muscle contraction, cell division, and cell motility (Dominguez and Holmes 2011; Pollard 2016).

The apicomplexans possess a single gene coding for actin (ACT1), except for the Plasmodium species, which also encode a second isoform (ACT2) mainly expressed in the gametocytes and mosquito stages (Deligianni et al. 2011) (Table 14.2). PfACT2 plays a critical role in gametogenesis and its deletion cannot be complemented by PfACT1 (Deligianni et al. 2011; Vahokoski et al. 2014). Actin filaments cannot be readily observed in the parasites. It appears to be mainly globular (Dobrowolski et al. 1997; Schmitz et al. 2005), and the generated filaments tend to be short and unstable (Schmitz et al. 2005; Sahoo et al. 2005). The inherent instability of apicomplexan F-actin resides both in its amino acid sequence, which is distant from other eukaryotic actins (Schüler et al. 2005a; Skillman et al. 2011; Pospich et al. 2017; Douglas et al. 2018), and in its regulation by a limited and divergent set of actin-binding proteins (ABPs) compared to most eukaryotic cells (Baum et al. 2006; Schüler and Matuschewski 2006) (Table 14.2). Yet, actin filaments are essential for parasite growth (Skillman et al. 2011) and especially for motility (Egarter et al. 2014; Drewry and Sibley 2015), suggesting a tight spatial and temporal regulation of the polymerization process within the parasites.

Actin dynamics have been carefully examined in vitro with recombinant TgACT1 and PfACT1 purified from the baculovirus insect cell expression system. TgACT1 polymerization was reported to follow an unconventional isodesmic model in which each monomer has the same assembly/disassembly rate in the polymer. Consequently, the polymerization rate is slow without a lag phase or critical concentration, and increases proportionally to the number of actin molecules (Skillman et al. 2013). In contrast, PfACT1 polymerization is reported to follow a classical nucleation-elongation model in which a slow nucleation step precedes a more rapid polymerization phase after reaching a critical concentration (Kumpula et al. 2017). Although the critical concentration and the polymerization rate of PfACT1 are similar to the canonical actin, structural and biochemical studies demonstrated that its depolymerization is faster, likely due to the inherent instability of the filaments (Vahokoski et al. 2014; Pospich et al. 2017). Indeed, despite a conserved location of the monomer interface, substitution of several residues in PfACT1 compared to rabbit actin weaken the interaction within the filament (Pospich et al. 2017; Kumpula et al. 2019). Interestingly, point mutations generated in both Toxoplasma and Plasmodium to stabilize F-actin revealed that filament instability is in fact essential for the survival of these parasites (Skillman et al. 2011; Douglas et al. 2018).

\subsubsection{A Large Pool of Globular Actin}

Actin turnover is fine-tuned by actin-binding proteins (ABPs). Searches across the sequenced genomes revealed that the apicomplexans have a limited repertoire of actin regulators, ten times smaller than most eukaryotes (Gordon and Sibley 2005; Schüler and Matuschewski 2006). These ABPs include a monomer-binding profilin (PRF), a F-actin-binding coronin (COR), filamentsevering actin-depolymerizing factors (ADFs), and F-actin-capping proteins (CPs) (Table 14.2). The apicomplexans lack one of the main regulators of actin dynamics, the actin-related protein2/3 (ARP2/3) complex, which mediates nucleation and branching of actin filaments, and possess instead two formins (FRM1 and FRM2). A third formin (FRM3) is found in the parasites of the coccidian sub-group of Apicomplexa.

As discussed above, the vast majority of actin is not incorporated into filaments but rather maintained in its globular form. Unexpectedly, ADF and PRF have been identified as the main contributors of the maintenance of this actin pool. Indeed, in contrast to most eukaryotic ADF, api- 
Table 14.2 Actin, actin-related and actin-binding proteins in Toxoplasma gondii and Plasmodium berghei

\begin{tabular}{|c|c|c|c|c|c|c|c|c|c|c|}
\hline & Class & Gene name & Gene ID & $\begin{array}{c}\text { MW } \\
(k D a)\end{array}$ & Localization & $\begin{array}{l}\text { FS } \\
(\mathrm{Tg})\end{array}$ & $\begin{array}{l}\text { Ess } \\
(\mathrm{Pb})\end{array}$ & $\begin{array}{l}\text { Seq Sim. } \\
\text { (Tg) }\end{array}$ & $\begin{array}{l}\text { Seq Sim. } \\
\quad(\mathrm{Pb})\end{array}$ & PDB entry \\
\hline \multirow{15}{*}{$\begin{array}{l}\text { Filament } \\
\text { forming }\end{array}$} & \multirow{2}{*}{ Actin } & АCT1 & $\begin{array}{l}\text { TGME49_209030 } \\
\text { PBANKA_1459300 }\end{array}$ & 42 & Cytoplasm & -4.50 & $E$ & $84 \%$ & $82 \%$ & $\begin{array}{l}4 \mathrm{CBU} \\
4 \mathrm{CBW}\end{array}$ \\
\hline & & АCT2 & PBANKA_1030100 & 43 & cytoplasm (gametocyte) & & D & NA & $76 \%$ & 4CBX \\
\hline & \multirow{9}{*}{$\begin{array}{l}\text { Actin- } \\
\text { like }\end{array}$} & ALP1 & $\begin{array}{l}\text { TGME49_219280 } \\
\text { PBANKA_0936900 }\end{array}$ & 46 & Cytoplasm & -2.53 & $\mathrm{~S}$ & $39 \%$ & $49 \%$ & \\
\hline & & ALP2a & $\begin{array}{l}\text { TGME49_248890 } \\
\text { PBANKA_0943300 } \\
\end{array}$ & 61 & NA & -4.54 & S & $27 \%$ & $20 \%$ & \\
\hline & & ALP2b & PBANKA_1104800 & 65 & NA & & n.d. & NA & n.d. & \\
\hline & & ALP3 & $\begin{array}{l}\text { TGME49_221410 } \\
\text { PBANKA_0212300 }\end{array}$ & 52 & NA & -1.50 & D & $23 \%$ & $36 \%$ & \\
\hline & & ALP5a & PBANKA_0811800 & 68 & NA & & n.d. & NA & n.d. & \\
\hline & & ALP5b & PBANKA_1007500 & 48 & NA & & n.d. & NA & n.d. & \\
\hline & & ALP8 & TGME49_294850 & 49 & NA & 0.59 & & $25 \%$ & NA & \\
\hline & & ALP9a & TGME49_234670 & 72 & NA & -2.59 & & $24 \%$ & NA & \\
\hline & & ALP9b & TGME49_269240 & 58 & NA & -0.37 & & n.d. & NA & \\
\hline & \multirow{4}{*}{$\begin{array}{l}\text { Actin- } \\
\text { related }\end{array}$} & ARP1 & $\begin{array}{l}\text { TGME49_248630 } \\
\text { PBANKA_0209300 }\end{array}$ & 42 & NA & -1.82 & n.d. & $53 \%$ & $63 \%$ & \\
\hline & & ARP4a & $\begin{array}{l}\text { TGME49_253040 } \\
\text { PBANKA_1020600 }\end{array}$ & 77 & NA & -4.16 & $E$ & $34 \%$ & $36 \%$ & \\
\hline & & ARP4b & TGME49_258050 & 60 & NA & -4.44 & & $27 \%$ & NA & \\
\hline & & ARP6 & $\begin{array}{c}\text { TGME49_257710 } \\
\text { PBANKA_0616800 }\end{array}$ & 67 & NA & -5.04 & D & $20 \%$ & $40 \%$ & \\
\hline $\begin{array}{l}\text { F-actin } \\
\text { binding }\end{array}$ & Coronin & COR & $\begin{array}{c}\text { TGME49_216970 } \\
\text { PBANKA_1464100 } \\
\end{array}$ & 68 & Cytoplasm & 0.71 & n.d. & $24 \%$ & $21 \%$ & 2AQ5 \\
\hline \multirow{2}{*}{$\begin{array}{l}\text { F-actin } \\
\text { capping }\end{array}$} & \multirow{2}{*}{$\begin{array}{c}\text { Capping } \\
\text { protein }\end{array}$} & $\mathrm{CPa}$ & $\begin{array}{l}\text { TGME49_208390 } \\
\text { PBANKA_1233900 }\end{array}$ & 47 & NA & 0.09 & $E$ & $15 \%$ & $19 \%$ & 2B0R \\
\hline & & $\mathrm{CPb}$ & $\begin{array}{l}\text { TGME49_219290 } \\
\text { PBANKA_1232400 }\end{array}$ & 36 & NA & -1.30 & D & $29 \%$ & $25 \%$ & \\
\hline \multirow{4}{*}{$\begin{array}{l}\text { G-actin } \\
\text { sequestering }\end{array}$} & Profilin & PRF & $\begin{array}{l}\text { TGME49_293690 } \\
\text { PBANKA_0833000 }\end{array}$ & 18 & Cytoplasm & -4.58 & $\mathrm{~S}$ & $16 \%$ & $18 \%$ & $\begin{array}{c}\text { 2JKF 2KJG } \\
\text { 3NEC }\end{array}$ \\
\hline & \multirow{2}{*}{$\begin{array}{l}\text { Cofilin/ } \\
\text { ADF }\end{array}$} & ADF1 & $\begin{array}{l}\text { TGME49_220400 } \\
\text { PBANKA_1137500 }\end{array}$ & 13 & Cytoplasm & -4.23 & n.d. & $27 \%$ & $21 \%$ & $\begin{array}{c}\text { 3Q2B } 2 \text { XF1 } \\
\text { 2L72 }\end{array}$ \\
\hline & & ADF2 & PBANKA_1103100 & 14 & NA & & $E$ & NA & $25 \%$ & 2XFA \\
\hline & $\begin{array}{l}\text { Cylase-associated } \\
\text { protein }\end{array}$ & CAP & $\begin{array}{l}\text { TGME49_310030 } \\
\text { PBANKA_0208000 }\end{array}$ & 225 & NA & 1.17 & n.d. & NA & NA & \\
\hline \multirow{3}{*}{$\begin{array}{l}\text { F-actin } \\
\text { nucleators }\end{array}$} & \multirow{3}{*}{ Formins } & FRM1 & $\begin{array}{l}\text { TGME49_206430 } \\
\text { PBANKA_1245300 }\end{array}$ & 547 & Apical pole & -3.24 & n.d. & n.d. & n.d. & \\
\hline & & FRM2 & $\begin{array}{l}\text { TGME49_206580 } \\
\text { PBANKA_1434600 }\end{array}$ & 492 & Cytoplasm, juxtanuclear region & -1.12 & n.d. & n.d. & n.d. & \\
\hline & & FRM3 & TGME49_213370 & 299 & Residual body & -2.79 & & n.d. & NA & \\
\hline & & & & & & \multicolumn{2}{|c|}{$\begin{array}{r}\text { E: Essential } \\
\text { S: slow } \\
\text { D: dispensable } \\
\text { n.d.: no data }\end{array}$} & \multicolumn{3}{|c|}{$\begin{array}{l}\text { Similarity with (BLAST-pairwise) } \\
\text { Oryctolagus cuniculus (rabbit) } \\
\text { TgACT1 }\end{array}$} \\
\hline
\end{tabular}

The GeneID corresponds to the accession numbers of EuPathDB. The references for the localization are cited in the text. The fitness scores are from the CRISPR-Cas9 genome wide screen performed on T. gondii (Sidik et al. 2016) and the PlasmoGEM database established for the erythrocytic stages of Plasmodium berghei in mice (Bushell et al. 2017). The sequence similarity (Seq. Sim.) is denoted as a percentage relative to the counterpart in the rabbit Oryctolagus cuniculus (grey) or TgACT1 (blue). The solved structures of the proteins can be accessed via the RCSB Protein Data Bank (PDB). The genes in purple are specific to Plasmodium species

complexan ADF (or ADF1 in Plasmodia) does not contain the typical F-actin-binding site and therefore prevents actin polymerization by sequestering G-actin (Schüler et al. 2005b; Mehta and Sibley 2010; Singh et al. 2011; Yadav et al. 2011; Baroni et al. 2018). Likewise, PRF appeared to sequester actin monomers and prevent their incorporation into filaments (Skillman et al. 2012), while in other eukaryotes, the presence of PRF usually enhances the polymerization rate of the formin nucleators by increasing the local concentration of ATP-actin in the vicinity of the growing filaments (Pollard 2016). Despite divergence in the amino acids sequences, the apicomplexan PRF shares an overall common structure with mammalian PRFs with the exception of an additional region composed of an acidic loop and a $\beta$-hairpin (Kursula et al. 2008; Kucera et al. 2010). This flexible region is a key determinant for interaction with actin but also serves as a recognition pattern in TgPRF to elicit the Toll-like receptor 11 (TLR11) innate immune response 
(Kucera et al. 2010; Moreau et al. 2017; Kadirvel and Anishetty 2018).

Another protein that has the capacity to bind G-actin and to regulate F-actin disassembly is the cyclase-associated protein or CAP (Table 14.2). In Apicomplexa, this protein harbors only a CARP domain able to interact and sequester G-actin and to promote the nucleotide exchange from ADP to ATP (Hliscs et al. 2010; Makkonen et al. 2013). CAP thus contributes to the abundant pool of G-actin, is important for the growth of tachyzoites, and appeared dispensable for the erythrocytic stages of malaria parasites but essential for oocyst development in the mosquito midgut (Hliscs et al. 2010; Hunt et al. 2019).

In the absence of ARP $2 / 3$ complex, the formins are the sole identified nucleators of F-actin in Apicomplexa. Formins are very large multidomain proteins $(>300 \mathrm{kDa})$ that interact with the barbed end of an actin filament, wherein actin nucleation activity is achieved by the formin homology 2 (FH2) domain (Pollard 2016). It was indeed confirmed, in both Toxoplasma and Plasmodium, that all the formins expressed were able to bind ACT1 and were potent nucleators of filamentous actin through their $\mathrm{FH} 2$ domain (Baum et al. 2008; Daher et al. 2010, 2012; Skillman et al. 2012). In both parasites, formins have been localized in subcellular locations where actomyosin systems participate for critical functions: PfFRM1 and TgFRM1 at the apical pole for motility, TgFRM2 in the cytoplasm at the apical juxtanuclear region involved in organelle positioning and inheritance, and TgFRM3 in the residual body implicated in cell-cell communication (Baum et al. 2008; Jacot et al. 2016; Stortz et al. 2018; Tosetti et al. 2019).

Growth of actin filaments is regulated by their polymerization but also by F-actin-binding proteins such as CPs, a family of proteins that binds the barbed end of F-actin and prevents the exchange with new subunits (Cooper and Sept 2008) and COR, a protein known to stabilize and bundle newly-formed filaments (de Hostos 1999). CPs have been investigated in P. berghei, and although their sequences differ from the mammalian counterparts, their folding and biochemical properties are preserved. Remarkably, the length of rabbit actin filaments was significantly decreased by the addition of the heterodimer $\mathrm{PbCP} \alpha / \beta$ (Ganter et al. 2009). In vivo, $\mathrm{PbCP} \alpha / \beta$ disruption has a strong impact on the malaria life cycle blocking the transmission of the parasites to a new host as described below (Ganter et al. 2009). In contrast, COR was shown to bind F-actin and increase its polymerization and crosslinking in Apicomplexa (Salamun et al. 2014; Olshina et al. 2015).

Overall, the intrinsic features of apicomplexan actin and ABPs contribute to the maintenance of a heterogeneous mixture of sequestered free G-actin and short filaments in these parasites. A fine-tuned coordination and regulation between the actin polymerization process and the action of ABPs is therefore needed to achieve specific and vital functions. The process is tightly regulated in time and space during parasite division but also during motility when actin filaments are crucial for the survival of the obligate intracellular parasites. All the ABPs have a critical role in the parasites' life cycle and their specific contribution to the regulation of the different actomyosin systems will be discussed below.

\subsection{Actomyosin Systems in Apicomplexa}

\subsubsection{Actin Polymerization Occurs at Specific Locations}

After decades of great limitation in visualization of actin filaments, unexpectedly, antibodies raised against Plasmodium ACT1 that preferentially recognized F-actin allowed for the observation of actin concentrated near the nucleus, at the periphery of motile parasites (ookinetes, sporozoites and merozoites), and at the moving junction during merozoite invasion (SidenKiamos et al. 2012; Angrisano et al. 2012). In gametocytes, the sexual stages of the malaria parasite, super-resolution and immuno-electron microscopy revealed the presence of an actin cytoskeleton underneath the IMC, along the 
microtubules with accumulation at the two poles of the parasite (Hliscs et al. 2015). Gametocytes express both ACT1 and ACT2, so it remains to be determined which one constitutes the observed actin cytoskeleton. More recently, actin chromobodies designed to visualize eukaryotic F-actin have been expressed in $T$. gondii and $P$. falciparum and revealed that polymerized actin is located in distinct subcellular compartments and at specific time points of the lytic cycle. In P. falciparum, they confirmed all the previous observations (Stortz et al. 2018). In T. gondii intracellular tachyzoites, F-actin was found at the apical perinuclear region, close to the apicoplast. In addition, an extensive F-actin network was stained in the residual body, which connects the basal pole of intravacuolar tachyzoites and organizes them into a rosette within the parasitophorous vacuole (Periz et al. 2017; Tosetti et al. 2019) (Fig. 14.2a, c). Remarkably, in extracellular tachyzoites, a ring of F-actin appears to be produced apically and to translocate to the rear of the parasite, co-localizing with the moving junction. Consequently, an accumulation of F-actin is observed as a dot at the basal pole of the parasites immediately after activation of motility (Tosetti et al. 2019).

Conditional knockout of TgACT1 and PfACT1 has recently been generated in $T$. gondii tachyzoites and P. falciparum erythrocytic stages, respectively (Andenmatten et al. 2013; Egarter et al. 2014; Drewry and Sibley 2015; Periz et al. 2017). As expected, absence of actin in both parasites is lethal, but the establishment of a dimerizable Cre-recombinase strategy that efficiently excises the loxP sites flanking the actin gene allowed scrutinizing all aspects of the parasite life cycle and dissecting the cellular functions for which actin is required. The localization of F-actin in both $T$. gondii and $P$. falciparum are in accordance with the location of the formins expressed by these parasites. The composition and role of the corresponding actomyosin systems are discussed below.

\subsubsection{Contribution of Actomyosin Systems to Cell Division Processes}

\subsubsection{Intravacuolar Connection and Cell-Cell Communication}

While in vitro cultures of $T$. gondii are asynchronous, the division of tachyzoites within a given parasitophorous vacuole is highly synchronized. The class XXIV TgMyoI, a fairly large myosin (approximately $200 \mathrm{kDa}$ ) with two predicted IQ motifs in its neck and no domain identified in its tail, was shown to be responsible for this phenomenon. TgMyoI localizes to the residual body and seems to be associated with the F-actin network, and importantly, TgFRM3 is present at the same location (Frénal et al. 2017b; Periz et al. 2017; Das et al. 2017; Tosetti et al. 2019). Knockout of TgMyoI or TgFRM3 had no impact on the fitness of the tachyzoites. Yet, the parasites appeared disorganized within the PV, failed to organize in rosettes, and divided in an asynchronous manner (Frénal et al. 2017b; Tosetti et al. 2019). The same phenotype was also observed in actin-depleted tachyzoites (TgACT1-cKO) (Periz et al. 2017). It was therefore hypothesized that an actomyosin system could be involved in the formation and/or maintenance of a basal connection between the parasites within the vacuole. Fluorescence recovery after photobleaching (FRAP) experiments performed on wild-type, TgMyoI-KO, TgFRM3-KO and TgACT1-cKO parasites demonstrated that soluble proteins from the cytoplasm but also from the nucleus were able to diffuse between the parasites of the same vacuole only when TgMyoI, TgFRM3 or TgACT1 were expressed (Frénal et al. 2017b; Periz et al. 2017; Tosetti et al. 2019).

These experiments identified the presence of an actomyosin system in the residual body, composed of TgMyoI that likely moves along actin filaments assembled by TgFRM3. This complex is involved in the formation and maintenance of a cytoplasmic connection between intravacuolar parasites allowing the diffusion of soluble proteins and metabolites to ensure a tightly synchro- 
nized division. Electron microscopy and 3D reconstruction revealed the presence of a tubular mitochondrion within the connection, passing through the basal complex and shared between intracellular parasites (Frénal et al. 2017b). This observation raises the possibility that diffusion or exchanges could occur between parasites through the mitochondrion as well. In addition, it has been shown that vesicles are also exchanged between the parasites along the actin filaments (Periz et al. 2017). It remains to be determined whether this transport is TgMyoI-dependent. Considering the extensive filamentous network present in the residual body, it is likely that ABPs influence the dynamics and structure of the network. Deletion of TgCAP, which modulates actin turnover through its G-actin sequestering activity, has a strong impact on the structure of the intravacuolar cell-cell connection and the arrangement in rosette of the parasites (Hunt et al. 2019). In this mutant, although the parasites are still connected and able to divide synchronously, the connections are really long, tubular, and not organized around a residual body. The endoplasmic reticulum was also observed within the connections suggesting a possible exchange of material through this organelle, just like the mitochondrion. However, diffusion of reporter protein was observed only between parasites in close proximity. These results open the question on the nature of the material that ensures synchronicity within the PV.

Of relevance, MyoI and FRM3 are only present in the genome of a few coccidians that divide by endodyogeny ensuring the communication that naturally exists in the other apicomplexans that divide by schizogony in the cytoplasm of the same cell (Tables 14.1 and Fig. 14.2c, d). Interestingly, this connection is not maintained in the bradyzoite stage, a latent and encysted form of $T$. gondii that grows slowly and asynchronously (Frénal et al. 2017b).

\subsubsection{Basal Pole Constriction and Cytokinesis}

At the end of cell division, the basal pole of the daughter cells constricts. In $T$. gondii, the class VI-like TgMyoJ has been associated with this process (Frénal et al. 2017b). MyoJ is a large myosin (approximately $270 \mathrm{kDa}$ ), but no IQ motif or other domains have been identified (Table 14.1). The protein is found in most apicomplexans and the chromerids (Foth et al. 2006; Mueller et al. 2017). It localizes at a ring-shaped structure at the basal end of the IMC in the developing daughter cells (Frénal et al. 2017b). At the end of division, this structure will constrict and form the posterior cup of the mature parasite $(\mathrm{Hu}$ 2008) (Fig. 14.2c). TgMyoJ colocalizes with the CaM-like protein centrin 2 (TgCEN2) at the posterior cup. In the absence of TgMyoJ, tachyzoites display an enlarged posterior pole and a loss of TgCEN2 staining. However, no problem in cytokinesis was observed in these parasites, which only exhibit a modest fitness defect in in vitro culture but in contrast a clear loss of virulence in the mouse model of infection (Frénal et al. 2017b). Conversely, depletion of TgCEN2 impacts the basal pole constriction although TgMyoJ remains associated with the enlarged basal cup. These results indicate that TgMyoJ and TgCEN2 play a role in the constriction of the tachyzoite basal pole, but it is not clear yet if they are directly associated with one another (Frénal et al. 2017b). One possibility is that TgCEN2 could act as a light chain for TgMyoJ.

Intriguingly, although loss of basal pole constriction has been observed in TgACT1-depleted tachyzoites demonstrating that it is an actindependent process (Periz et al. 2017), none of the three formins expressed by the parasites seems to be involved in this process (Tosetti et al. 2019). This suggests that either an unknown nucleator acts at the basal cup or that some F-actin can be formed in the absence of polymerizing factors possibly following the isodesmic model identified in vitro with recombinant TgACT1 (Skillman et al. 2013). This hypothesis is yet to be tested.

In $T$. gondii, depletion of TgACT1 (or TgMyoJ) does not affect the cytokinesis process that occurs naturally, releasing individual parasites during egress. In contrast, in $P$. falciparum, PfACT1 depletion leads to a cytokinesis defect with conjoined merozoites that egress from the infected erythrocytes (Das et al. 2017). The same phenotype was also observed in PfFRM2 depleted 
parasites, indicating that PfACT1 and PfFRM2 participate in cytokinesis of malaria schizonts (Das et al. 2017; Stortz et al. 2018). A defect in proper parasite segmentation has also been reported with the depletion of the newly identified basal complex protein PfCINCH (coordinator of nascent cell detachment). Interestingly, co-immunoprecipitation experiments performed on P. falciparum schizonts with PfCINCH identified several new proteins of the basal complex and pulled-down PfMyoJ suggesting that in malaria parasites, a basal actomyosin system is responsible for constriction of the schizont basal pole, but also cytokinesis prior egress (Rudlaff et al. 2019). As in T. gondii, PbMyoJ was successfully deleted in P. berghei without noticeable impact on its life cycle (Wall et al. 2019). Its endogenous tagging allowed its detection only in mature oocysts when sporozoites are formed. PbMyoJ localizes at the junction between the sporozoites and the residual bodies, consistent with a basal localization but remains associated with the oocyst body upon egress of the sporozoites (Wall et al. 2019). So far, it remains enigmatic how these different components contribute to the segregation of the schizonts, but these studies pave the way to a better understanding of the contractile ring, and the constriction and cytokinesis processes in Apicomplexa.

\subsubsection{Contribution of Actomyosin to Organelle Positioning and Inheritance}

Besides MyoA, the second myosin strictly conserved across the Apicomplexa is the class XXII MyoF, which interestingly also has orthologs in the chromerids $C$. velia and $V$. brassicaformis (Foth et al. 2006; Mueller et al. 2017). The function of MyoF has been characterized in $T$. gondii tachyzoites. TgMyoF possesses six predicted IQ motifs and a tail domain with seven WD40 and a coiled-coil domain suggesting that the protein might function as a dimer. Homology was found between $\mathrm{TgMyoF}$ and class $\mathrm{V}$ myosins that function as cargo transporters, moving organelles within the organism (Hammer and Sellers 2012;
Heaslip et al. 2016). No myosin light chain has been found associated with $\mathrm{TgMyoF}$ so far (Table 14.3). TgMyoF localizes in the cytoplasm of the parasites, particularly concentrated in the juxtanuclear region and in the vicinity of the dividing apicoplast (Jacot et al. 2013), where the actin nucleator TgFRM2 is also located (Tosetti et al. 2019). Taking advantage of the possibility that $\mathrm{TgMyoF}$ could form a dimer, its function was tackled by disrupting this dimer via overexpression of the tail of TgMyoF, with the aim to generate a non-functional heterodimer having a dominant-negative effect. TgMyoF was thus found to be essential for the survival of the tachyzoites and a severe defect in apicoplast inheritance was detected as well as a loss of the close positioning of the centrosomes on one side of the nucleus (Jacot et al. 2013). The same phenotype was also observed with the inducible knockout and knockdown of $\mathrm{TgMyoF}$ subsequently generated (Jacot et al. 2013; Heaslip et al. 2016). Concordantly, a defect in apicoplast inheritance was observed in TgACT1-depleted parasites as well as in the TgFRM2-KO strain (Periz et al. 2017; Tosetti et al. 2019). The same phenotype is also observed in the intraerythrocytic stages of $P$. falciparum depleted in PfACT1 or in PfFRM2 confirming the conservation of the machinery in Apicomplexa (Das et al. 2017; Stortz et al. 2018). In addition, $\mathrm{PbMyoF}$ is also likely essential in $P$. berghei since the attempts to delete the gene have been unsuccessful so far (Wall et al. 2019).

The primary function of MyoF is likely to maintain the positioning of the centrosomes during cell division. As a consequence of their mispositioning in TgMyoF mutants, the daughter cells grow in opposite directions within the mother parasite instead of growing side-by-side, and the recruitment and association of the apicoplast by the centrosomes are lost (Striepen et al. 2000; Jacot et al. 2013). Some rhoptry organelles also fail to be encapsulated in the progenies and enlarged residual bodies containing apicoplasts and rhoptries were observed. However, enough rhoptries are still accurately targeted to the apical pole and no defect in invasion was recorded in TgMyoF mutants (Jacot et al. 2013). TgMyoF 
Table 14.3 Myosin light chains in Toxoplasma gondii

\begin{tabular}{|c|c|c|c|c|c|}
\hline Gene name & $\begin{array}{l}\text { Associated } \\
\text { mysoin }\end{array}$ & Gene ID & $\begin{array}{l}\text { FS } \\
(\mathrm{Tg})\end{array}$ & $\begin{array}{l}\text { MW } \\
\text { (kDa) }\end{array}$ & Localization \\
\hline MLC1 & $\begin{array}{c}\text { MyoA - MyoB/C } \\
\text { MyoH }\end{array}$ & TGME49_257680 & -2.70 & 24 & Inner membrane complex \\
\hline MLC2 & MyoD & TGME49_297470 & 0.78 & 41 & Plasma membrane \\
\hline MLC3 & - & TGME49_250840 & -1.91 & 100 & Conoid \\
\hline MLC4 & - & TGME49_294390 & 0.38 & 19 & Endoplasmic reticulum \\
\hline MLC5 & MyoH & TGME49_311260 & -0.33 & 14 & Conoid \\
\hline MLC7 & MyoH & TGME49_315780 & -0.12 & 23 & Conoid \\
\hline ELC1a & MyоA - Муов/C & TGME49_269438 & 1.09 & 8 & Inner membrane complex \\
\hline ELC1b & MyоA - Myов/C & TGME49_269442 & 0.11 & 10 & Inner membrane complex \\
\hline ELC2 & MyoA & TGME49_305050 & 1.57 & 15 & Inner membrane complex \\
\hline CAM1 & Муон & TGME49_246930 & 1.09 & 19 & Conoid \\
\hline CAM2 & Myон & TGME49_262010 & -0.81 & 15 & Conoid \\
\hline CAM3 & Myoн & TGME49_226040 & -3.25 & 19 & Conoid \\
\hline
\end{tabular}

The GeneID corresponds to the accession numbers of EuPathDB. The fitness scores are from the CRISPR-Cas9 genome wide screen performed on T. gondii (Sidik et al. 2016). The references for the localization are cited in the text

was also identified as the motor responsible for the directed movement of the dense granules, in agreement with the fact that this movement is an actin-dependent process (Heaslip et al. 2016). TgCAP has been shown to regulate the trafficking of the dense granules, given that the deletion of this ABP causes the organelles to move further distances and at higher speeds (Hunt et al. 2019). These findings support the fact that TgMyoF might function as class $\mathrm{V}$ myosin motors transporting organelles inside cells (Hammer and Sellers 2012). TgMyoF has been also found associated with the acylated protein ARO (armadillorepeat only) anchored at the surface of the rhoptries and whose depletion leads to the dispersion of mature rhoptry organelles in the cytoplasm, preventing the invasion process to occur (Mueller et al. 2013). Yet, apical rhoptry positioning does not appear to be an actin-dependent process since these organelles are not impacted in the absence of TgACT1 (Egarter et al. 2014; Drewry and Sibley 2015). TgMyoF might play a role in tethering the newly-made rhoptries to the apical part of the developing daughter cells, where they are actually found to accumulate, in addition to the vicinity of the apicoplast (Jacot et al. 2013). Such a tethering function of myosin class Va has been observed for melanosomes in mouse melanocytes for their long-distance transport on microtubules (Hammer and Sellers 2012). We might hypothesize that rhoptries made de novo are first tethered by TgMyoF and then transported longer distances by microtubule-binding motor(s), explaining why some rhoptries are found lost in the residual body while most of them are still accurately transported and anchored to the apical pole (Lentini et al. 2019). Alternatively, the rhoptries observed in the residual body might be the ones of the mother that were not properly recycled during the cell division process. 
Interestingly, $\mathrm{TgMyoF}$ is also found in chromerids, which possess a photosynthetic plastid. It is likely that the function of TgMyoF in positioning of the centrosomes and inheritance of the plastid is conserved in these organisms.

\subsubsection{Vital Contribution of the Actomyosin System to Motility}

MyoA has been identified in T. gondii as the motor responsible for the motility of the tachyzoite, powering the movement within the glideosome complex (Meissner et al. 2002). Conditional depletion of this motor clearly demonstrated its critical role for invasion of and egress from the host cell as well as virulence in mice. In P. berghei, a promoter-swap strategy has been used to down-regulate PbMyoA in the motile ookinete stage (Siden-Kiamos et al. 2011). This demonstrated the essential role of the protein for motility since no sign of productive gliding locomotion was recorded. As a consequence, the formation of oocysts was completely abolished and no sporozoite were found to be transmitted from the mosquito to a new host.

MyoA belongs to the class XIV myosins and is conserved across the phylum Apicomplexa (Table 14.1). It is one of the smallest myosins (93 kDa), exhibiting a short neck domain with degenerated IQ motifs and no tail (Heintzelman and Schwartzman 1997; Herm-Götz et al. 2002). Moreover, MyoA lacks two key conserved residues in the motor domain, one in the actinbinding surface loop and one in the pivot-point for the motion of the lever arm.

TgMyoA was the first apicomplexan motor that has been directly purified from the parasites for biochemical and biophysical characterization (Herm-Götz et al. 2002). TgMyoA is a monomeric and plus-end-directed motor and despite its unusual features, it exhibits the kinetic properties and velocity of a fast myosin such as the conventional skeletal muscle myosins designed to generate movement rather than force. TgMyoA is non-processive and likely functions in the context of large motor arrays. MyoA localizes to the periphery of the tachyzoites and all motile stages of Plasmodium, in tight association with the membrane, a localization dependent on a dibasic motif (two arginines) conserved across the phylum (Hettmann et al. 2000; Green et al. 2017). One myosin light chain (MLC) and one essential light chain (ELC) have been associated with TgMyoA and PfMyoA (Nebl et al. 2011; Williams et al. 2015; Bookwalter et al. 2017; Green et al. 2017) (Table 14.3). TgMLC1, named MyoA-tail interacting protein (MTIP) in Plasmodia, is conserved throughout the phylum and is unusual, presenting a long $\mathrm{N}$-terminal extension of 70 residues preceding the CaM-like domain composed of degenerated EF-hands (Herm-Götz et al. 2002; Bergman et al. 2003). The solved structures of the CaM-like domain of TgMLC1 and PfMTIP bound to the neck of MyoA revealed a conserved clamping conformation of the EF-hands around the posterior region of the neck and a buried electrostatic surface between the two proteins as found for other myosin heavy/light chain interaction previously determined (Bosch et al. 2007; Powell et al. 2017). However, this binding is not influenced by the presence of calcium (Green et al. 2006; Bookwalter et al. 2014). In addition, dissection of TgMLC1 mutants in $T$. gondii identified the $\mathrm{N}$-terminal extension as responsible for the localization of TgMyoA at the IMC, thus substituting for the role of the myosin heavy chain tail that TgMyoA lacks (Frénal et al. 2010). Upstream of the MLC1/MTIP binding site, one essential light chain has been identified first in $T$. gondii and very recently in Plasmodium species (Nebl et al. 2011; Bookwalter et al. 2017; Green et al. 2017). Surprisingly, the sequence identity between TgELC and PfELC is low (approximately 20\%) and prevented the identification of PfELC based on homology search (Bookwalter et al. 2017; Green et al. 2017). In fact, in T. gondii, two ELCs, named TgELC1 and TgELC2, compete for the same binding site on the neck of TgMyoA, but TgELC1 is likely and predominantly bound since it was the only one identified by mass spectrometry following co-immunoprecipitation of the glideosome (Nebl et al. 2011; Williams et al. 2015). TgELC1 and TgELC2 are individually 
dispensable but cannot be deleted at the same time. Indeed, their contribution to the glideosome complex is essential since their disruption totally destabilizes TgMyoA (Williams et al. 2015). The same is true for the myosin light chain. When TgMLC1 is depleted in tachyzoites or when PbMTIP is depleted in P. berghei ookinetes, TgMyoA and PbMyoA are also fully depleted (Sebastian et al. 2012; Egarter et al. 2014). Therefore, the myosin light chain MTIP/MLC1 is essential in both species.

Until recently, it had not been possible to produce soluble and functional apicomplexan myosins from heterologous expression systems, which hampered structural assessment of the unusual features of MyoA and its bound light chains. Remarkably, in 2014, Bookwalter et al. identified the ortholog of the striated muscle myosin-specific co-chaperone of the UCS protein family, Unc45b, in the T. gondii genome (Bookwalter et al. 2014). They succeeded in producing soluble and functional TgMyoA/TgMLC1 and TgMyoA/TgMLC1/TgELC1 complexes by co-expressing these proteins in the presence of the co-chaperone TgUNC. This not only led to the determination of the kinetics of the motor in the presence of its light chains in both $T$. gondii (Bookwalter et al. 2014) and P. falciparum (Bookwalter et al. 2017) but also to structural insight of TgMyoA bound to its light chains (Powell et al. 2017, 2018). In both parasites, it was elegantly demonstrated with the in vitro motility assay that the binding of ELC in addition to MLC/MTIP doubles the speed of the actin movement (Bookwalter et al. 2014, 2017). ELC binds upstream of MLC to the neck domain of MyoA but also to the converter of the head domain (Powell et al. 2017). With the two bound light chains, the length and stability of the lever arm is increased and optimized for force transduction. Interestingly, binding of ELC and MLC is cooperative and requires first binding of MLC to MyoA (Bookwalter et al. 2017; Powell et al. 2017). This could be due to the fact that TgMyoA needs TgMLC1 for its localization in vivo (Frénal et al. 2010), a possible pre-requisite for the binding of TgELC1.
The crystal structure of TgMyoA solved in complex with the CaM-like domain of TgMLC1 was an important step forward. It revealed that mutations of the key residues implicated in binding to actin and in the function of the motor domain are a clear adaptation to the divergent TgACT1 and create new interactions that maintain and possibly enhance the transduction of the force from the active site to the lever arm (Powell et al. 2018). These results unravel the mystery of MyoA being a bona fide fast motor despite its unusual features.

It remains to be determined how the function of the motor is regulated. Calcium seems to regulate the assembly of the motor complex since the cooperative binding of the light chains to MyoA is further increased in the presence of calcium (Powell et al. 2017). Phosphorylation of TgMyoA and PfMyoA appear to modulate rather than activate the motor since phospho-mimetic mutants enhanced the affinity for actin filaments and the speed of their displacement in vitro (Bookwalter et al. 2017; Powell et al. 2018). In vivo, some phosphorylation sites on TgMyoA seem to be important for the activation of the motility while no site on TgMLC1 was found to be critical to modulate gliding (Jacot et al. 2014; Gaji et al. 2015).

Unexpectedly, the gene coding for $T g M y o A$ has been successfully deleted in $T$. gondii tachyzoites (Andenmatten et al. 2013). Parasites could be maintained in culture although their lytic cycle was severely impacted with a strong defect in motility, invasion, and egress. The isolation of this mutant raised the question of how some motility can still be achieved without TgMyoA. The identification of a second glideosome complex similar to the initial one but located at the basal ring of the parasite, which includes the class XIV TgMyoC instead of TgMyoA, raised the possibility of a functional complementation between the complexes, especially because $\mathrm{TgMyoC}$ shares the two light chains TgMLC1 and TgELC1 with TgMyoA (Frénal et al. 2014). Indeed, in the absence of $\mathrm{TgMyoA}$, a relocalization of $\mathrm{TgMyoC}$ along the pellicle was observed, highlighting the plasticity and adaptation of the parasite to ensure comple- 
tion of the vital step of host cell invasion (Frénal et al. 2014, 2017b). Accordingly, parasite clones with a simultaneous deletion of $M y o A$ and $M y o B / C$ could not be isolated (Egarter et al. 2014). In contrast to MyoA, MyoC is not conserved across the Apicomplexa, especially in Plasmodium species (Table 14.1). In these parasites, MyoA is therefore likely essential for motility as in $P$. berghei ookinete wherein downregulation of $\mathrm{PbMyoA}$ completely abrogated gliding and blocked the life-cycle progression of the parasite into the mosquito vector (SidenKiamos et al. 2011).

A third motor from the class XIV, TgMyoH, has been found to be crucially involved in motility of the tachyzoites (Graindorge et al. 2016). $\mathrm{TgMyoH}$ is located in the conoid, at the apex of the parasites, and its conditional depletion led to a severe defect in motility, invasion, and egress from the infected cells. Invasion experiments demonstrated that, in contrast to wild-type parasites that completed invasion, $\mathrm{TgMyoH}$-depleted parasites were attached to the surface of the host cell by their tip, forming a moving junction that cannot be translocated along the parasite body. In the same experiment, TgMyoA-depleted parasites were engaged in the penetration into the host cell, but most of them stopped at the level where the IMC starts. These results indicate that a relay of myosins is involved in the translocation of the adhesins along the parasites with $\mathrm{TgMyoH}$ initiating the process at the apex until the edge of the IMC, then TgMyoA along the pellicle and finally $\mathrm{TgMyoC}$ at the basal ring (Fig. 14.3). Noteworthy in this context, in the absence of TgMyoC, TgMyoA is additionally found at the basal ring (Frénal et al. 2014). The precise role of TgMyoC is therefore unknown, but it might be involved in the parasite twisting motion observed at the very end of the invasion process that enables sealing of the PV (Pavlou et al. 2018).

TgMyoH belongs to class XIV and orthologs are found in other coccidians such as Eimeria and Cryptosporidium that harbor a conoid but also in piroplasma such as Theileria and Babesia that do not (Table 14.1) (Mueller et al. 2017). However, no direct ortholog has been identified in Plasmodium species. Its sequence predicts a neck region with eight IQ motifs and a tail harboring three $\alpha$-tubulin suppressor 1 (ATS1) or RCC1 (Regulator of chromosome condensation 1) domains. These domains target $\mathrm{TgMyoH}$ to the apex of the parasite, linking directly or not TgMyoH to the conoid fibers (Graindorge et al. 2016). Six CaM-containing domain proteins have been found associated with TgMyoH (Graindorge et al. 2016; Long et al. 2017). Four of them, TgMLC5, TgCaM1, TgCaM2, and TgCaM3, are only associated with $\mathrm{TgMyoH}$, since their apical localization is disrupted when $\mathrm{TgMyoH}$ is downregulated, but no difference in the localization of the two others, TgMLC1 and TgMLC7, was observed. In addition to TgMLC1, only TgCaM3 appears essential for tachyzoite survival (Long et al. 2017) (Table 14.3). The function of this protein is not dependent on the presence of calcium, suggesting a structural role of $\mathrm{TgCaM} 3$ in the neck domain of $\mathrm{TgMyoH}$, in contrast to TgCaM1 and $\mathrm{TgCaM} 2$, which might have a regulatory role since their function is calcium-dependent (Long et al. 2017).

While no direct ortholog of $\mathrm{TgMyoH}$ has been found in Plasmodium species, $\mathrm{PbMyoB}$, which was characterized in $P$. berghei, might be a functional homolog (Yusuf et al. 2015). PbMyoB, like TgMyoH, belongs to myosin class XIVc, but it is significantly smaller since it exhibits a shorter neck with one predicted IQ motif and no tail (Foth et al. 2006). PbMyoB has been localized at the extreme apical pole, likely at the apical polar rings, of all the motile forms of the parasite (merozoite, ookinete and sporozoite). Its associated light chain, PbMLC-B, is quite atypical being very long (652 aa) and possessing two coiled-coil domains, similar to TgMLC3, which is also found at the apex of the tachyzoite (Graindorge et al. 2016). Functional studies would be needed to determine the role of this complex in Plasmodium, although $\mathrm{PbMyoB}$ appeared dispensable both in the high throughput knockout screen of $P$. berghei genes (Bushell et al. 2017) as well as a specific reverse genetics approach (Wall et al. 2019). In contrast, PbMyoE is found at the basal pole of the motile ookinete and sporozoite (Table 14.1), and its deletion severely impacts the motility of the sporozoite (Wall et al. 2019). 
In line with the role of myosin motors, TgACT1 and PfACT1 have been shown to be essential for gliding motility. T. gondii tachyzoites are severely impaired in their motility, invasion capacity and exit from the infected cell (Egarter et al. 2014; Drewry and Sibley 2015). In contrast, although invasion of the erythrocyte by $P$. falciparum merozoites is completely abolished in the absence of actin, egress is not (Das et al. 2017). For both parasites, egress involves the rupture the parasitophorous vacuole membrane and the host cell plasma membrane, which is assisted by the release of perforins from the micronemes (Kafsack et al. 2009; Garg et al. 2013). While the tachyzoite needs to impose an additional mechanical pressure on the membranes applied by its motility to exit the cell (Meissner et al. 2002; Plattner et al. 2008; Frénal et al. 2010; Mehta and Sibley 2011; Graindorge et al. 2016; Jacot et al. 2016), the schizonts activate parasite and host proteases that destabilize the cytoskeleton of the red blood cell, and it is not clear that motility is required (Millholland et al. 2011). The actin depletion performed in Plasmodium indicates that motility is absolutely required during invasion for the moving junction to progress backward along the parasite but not for egress, for which the destabilization of the erythrocyte cytoskeleton and then the curling of the red blood cell membrane might be sufficient to eject the merozoites into the bloodstream (Das et al. 2017).

\subsection{ABPs Regulate the Function of the Actomyosin Systems}

ABPs that influence actin turnover have obvious impacts on the function of the actomyosin systems. The two main actin monomer-sequestering proteins, ADF and PRF, have been shown to have a strong impact on motility, invasion, and egress of T. gondii and P. berghei (Plattner et al. 2008; Mehta and Sibley 2011; Moreau et al. 2017). In addition, depletion of TgADF and TgPRF also revealed a defect in the inheritance of the plastidlike apicoplast in daughter cells (Jacot et al.
2013). Contrastingly, the G-actin-sequestering protein TgCAP, which is also critical for gliding motility, invasion, and egress of $T$. gondii, as well as for dense-granule trafficking and parasite connection, has no influence on apicoplast inheritance (Hunt et al. 2019). These observations reflect the different spatial requirements for actin turnover within the parasite. In Plasmodium, $\mathrm{PbCAP}$ has an essential role only in the oocyst stage within the mosquito (Hliscs et al. 2010). In the absence of PbCAP, maturation of the oocysts is compromised and no sporozoites are formed, preventing transmission of parasites from the mosquito to a new host.

The growth of actin filaments is regulated by capping proteins. The heterodimer $\mathrm{PbCP} \alpha / \beta$ has the ability to decrease the length of rabbit actin filaments in vitro (Ganter et al. 2009). In vivo, disruption of $\mathrm{PbCP} \beta$ had no impact on the erythrocytic cycle of the parasite, but in the Anopheles mosquito vector, the sporozoites displayed a strong defect in motility preventing them from colonizing the salivary glands and therefore blocking transmission of the parasites to a new host (Ganter et al. 2009). Unexpectedly, $\mathrm{PbCP} \alpha$ appears to be essential alone in the erythrocytic cycle likely working as a homodimer, but its precise role has not been assessed yet (Ganter et al. 2015). One hypothesis for the split role of these dimers is the environment-dependent function with $\mathrm{PbCP} \alpha / \beta$ working at ambient temperature in the mosquito while the $\mathrm{PbCP} \alpha$ homodimer could be adapted to the warm-blooded host.

Actin polymerization is also regulated by coronin (COR). Both TgCOR and PfCOR are able to bind F-actin and increase its polymerization and bundling in vitro (Salamun et al. 2014; Olshina et al. 2015). Deletion of TgCOR revealed that this protein is not essential in tachyzoites with only a modest effect on the invasion and egress steps of the lytic cycle (Salamun et al. 2014). Yet, interestingly, TgCOR is cytosolic but strikingly relocalizes to the posterior pole in motile parasites, independently of actin dynamics but concomitantly to microneme secretion (Salamun et al. 2014). This suggests that TgCOR could play a role in endocytosis and membrane 
recycling linked to the microneme exocytosis to eliminate excessive accumulation of membranes at the posterior pole and preserve the pellicle integrity. A relocalization from the periphery to the rear of the parasite has also been observed in the sporozoite of $P$. berghei during motility, but this time in an actin-dependent manner occurring downstream of the calcium-signaling cascade leading to microneme secretion (Bane et al. 2016). Sporozoites lacking $\mathrm{PbCOR}$ are impaired in motility and in their ability to colonize the salivary glands of the Anopheles mosquito (Bane et al. 2016). Recently, PfCOR has also been associated with artemisinin resistance. Indeed, longterm in vitro culture of $P$. falciparum cell lines under dihydroartemisinin selection allowed the isolation of mutants presenting several point mutations in the beta-propeller region of PfCOR (Demas et al. 2018). After PfKelch13, PfCOR is the second gene demonstrated to confer reduced artemisinin susceptibility and the conservation of the beta-propeller motif in the two proteins suggests a common mechanism of resistance and the possible emergence of PfCOR mutants in nature.

\subsection{Conclusion}

Over the last decade, a big step forward has been made in elucidating the role of myosin heavy chains, visualizing actin filaments, and characterizing regulatory ABPs in Toxoplasma and Plasmodium. This led to the identification of actomyosin systems serving three major processes in these parasites; (i) organelle trafficking, positioning and inheritance, (ii) basal pole constriction and intravacuolar cell-cell connection and (iii) motility, invasion, and egress. Until recently, it was really challenging to purify soluble and functional apicomplexan myosin heavy chains from heterologous systems. The identification of the T. gondii homolog of a myosinspecific co-chaperone of the UCS (UNC-45/ CRO1/She 4p) family changed this and has been a key factor in producing TgMyoA and its light chains from the baculovirus/Sf9 insect cell expression system (Bookwalter et al. 2014). This allowed in-depth biochemical and structural characterization of TgMyoA/TgMLC1 and TgMyoA/TgMLC1/TgELC1 complexes uncovering mechanistic and regulatory aspects of these interactions (Bookwalter et al. 2014; Powell et al. 2017, 2018). Functional study of the chaperone TgUNC in $T$. gondii tachyzoites demonstrated that it is indeed a bona fide myosin chaperone in the parasite (Frénal et al. 2017b). All 11 myosin heavy chains expressed were destabilized upon depletion of TgUNC, and the phenotype of its down-regulation is a combination of the phenotypes of each myosin heavy chain described previously.

The repertoire of myosin heavy chains has been localized in both Toxoplasma and Plasmodium, and all the essential motors have been functionally characterized in $T$. gondii (Wall et al. 2019; Jacot et al. 2013; Graindorge et al. 2016; Frénal et al. 2017b). It remains now to assess the function of the myosin heavy chains in Plasmodium and to identify the components of the different actomyosin systems, especially the proteins of the basal complex that could be involved in the constriction and cytokinesis of the parasites, a process shared by all the parasites of the phylum. To understand the function and regulation of the myosin heavy chains, it also remains to identify the associated myosin light chains (MLCs). Several of them have been localized in T. gondii (Polonais et al. 2011) (Table 14.3) but not yet demonstrated as being associated with a motor. The limited repertoire of classical MLCs suggests that some other EF-hand-containing proteins could act as myosin light chains. Three calmodulins (TgCAM1-3) have been identified as light chains for $\mathrm{TgMyoH}$ (Long et al. 2017), and it might be worth exploring the possibility that some centrins could also play this role, especially TgCEN2, which shares the same function as TgMyoJ in the basal complex constriction.

A better understanding of the dynamics of the actomyosin system has been provided by the biochemical and functional characterization of ABPs that unraveled unusual features of these proteins compared to other eukaryotes. The genome of Toxoplasma and Plasmodium further encodes a 
large repertoire of actin-like and actin-related proteins that has not yet been explored, with several of them being likely critical for the survival of the parasites as suggested by the genome wide screens (Table 14.2). Characterization of these proteins should provide new insights on the contribution of actomyosin systems to the diverse cellular functions of the parasite.

\section{References}

Andenmatten N, Egarter S, Jackson AJ et al (2013) Conditional genome engineering in Toxoplasma gondii uncovers alternative invasion mechanisms. Nat Methods 10:125-127. https://doi.org/10.1038/ nmeth.2301

Angrisano F, Riglar DT, Sturm A et al (2012) Spatial localisation of actin filaments across developmental stages of the malaria parasite. PLoS One 7:e32188. https://doi.org/10.1371/journal.pone.0032188

Bane KS, Lepper S, Kehrer J et al (2016) The actin filament-binding protein coronin regulates motility in Plasmodium Sporozoites. PLoS Pathog 12:e1005710. https://doi.org/10.1371/journal.ppat.1005710

Baroni L, Pereira LM, Maciver SK, Yatsuda AP (2018) Functional characterisation of the actindepolymerising factor from the apicomplexan Neospora caninum (NcADF). Mol Biochem Parasitol 224:26-36. https://doi.org/10.1016/j. molbiopara.2018.07.008

Baum J, Papenfuss AT, Baum B et al (2006) Regulation of apicomplexan actin-based motility. Nat Rev Microbiol 4:621-628. https://doi.org/10.1038/nrmicro1465

Baum J, Tonkin CJ, Paul AS et al (2008) A malaria parasite formin regulates actin polymerization and localizes to the parasite-erythrocyte moving junction during invasion. Cell Host Microbe 3:188-198. https://doi. org/10.1016/j.chom.2008.02.006

Bergman LW, Kaiser K, Fujioka H et al (2003) Myosin A tail domain interacting protein (MTIP) localizes to the inner membrane complex of Plasmodium sporozoites. J Cell Sci 116:39-49

Bichet M, Joly C, Henni AH et al (2014) The toxoplasmahost cell junction is anchored to the cell cortex to sustain parasite invasive force. BMC Biol 12:773. https:// doi.org/10.1186/s12915-014-0108-y

Bookwalter CS, Kelsen A, Leung JM et al (2014) A Toxoplasma gondii class XIV myosin, expressed in Sf9 cells with a parasite co-chaperone, requires two light chains for fast motility. J Biol Chem 289:3083230841. https://doi.org/10.1074/jbc.M114.572453

Bookwalter CS, Tay CL, McCrorie R et al (2017) Reconstitution of the core of the malaria parasite glideosome with recombinant Plasmodium class XIV myosin A and Plasmodium actin. J Biol Chem 292:1929019303. https://doi.org/10.1074/jbc.M117.813972
Bosch J, Turley S, Roach CM et al (2007) The closed MTIP-myosin A-tail complex from the malaria parasite invasion machinery. J Mol Biol 372:77-88. https:// doi.org/10.1016/j.jmb.2007.06.016

Bushell E, Gomes AR, Sanderson T et al (2017) Functional profiling of a plasmodium genome reveals an abundance of essential genes. Cell 170:260-272.e8. https://doi.org/10.1016/j.cell.2017.06.030

Cooper JA, Sept D (2008) New insights into mechanism and regulation of actin capping protein. Int Rev Cell Mol Biol 267:183-206. https://doi.org/10.1016/ S1937-6448(08)00604-7

Daher W, Plattner F, Carlier M-F, Soldati-Favre D (2010) Concerted action of two formins in gliding motility and host cell invasion by Toxoplasma gondii. PLoS Pathog 6:e1001132. https://doi.org/10.1371/journal. ppat. 1001132

Daher W, Klages N, Carlier M-F, Soldati-Favre D (2012) Molecular characterization of Toxoplasma gondii formin 3 , an actin nucleator dispensable for tachyzoite growth and motility. Eukaryot Cell 11:343-352. https://doi.org/10.1128/EC.05192-11

Das S, Lemgruber L, Tay CL et al (2017) Multiple essential functions of Plasmodium falciparum actin-1 during malaria blood-stage development. BMC Biol 15:70. https://doi.org/10.1186/ s12915-017-0406-2

de Hostos EL (1999) The coronin family of actinassociated proteins. Trends Cell Biol 9:345-350

Deligianni E, Morgan RN, Bertuccini Let al (2011) Critical role for a stage-specific actin in male exflagellation of the malaria parasite. Cell Microbiol 13:1714-1730. https://doi.org/10.1111/j.1462-5822.2011.01652.x

Demas AR, Sharma AI, Wong W et al (2018) Mutations in Plasmodium falciparum actin-binding protein coronin confer reduced artemisinin susceptibility. Proc Natl Acad Sci U S A 115:12799-12804. https://doi. org/10.1073/pnas.1812317115

Dobrowolski JM, Niesman IR, Sibley LD (1997) Actin in the parasite Toxoplasma gondii is encoded by a single copy gene, ACT1 and exists primarily in a globular form. Cell Motil Cytoskeleton 37:253-262. https://doi. org/10.1002/(SICI)1097-0169(1997)37:3<253::AID$\mathrm{CM} 7>3.0 . \mathrm{CO} ; 2-7$

Dominguez R, Holmes KC (2011) Actin structure and function. Annu Rev Biophys 40:169-186. https://doi. org/10.1146/annurev-biophys-042910-155359

Douglas RG, Nandekar P, Aktories J-E et al (2018) Intersubunit interactions drive divergent dynamics in mammalian and Plasmodium actin filaments. PLoS Biol 16:e2005345. https://doi.org/10.1371/journal. pbio. 2005345

Drewry LL, Sibley LD (2015) Toxoplasma actin is required for efficient host cell invasion. MBio 6:e00557. https://doi.org/10.1128/mBio.00557-15

Egarter S, Andenmatten N, Jackson AJ et al (2014) The toxoplasma Acto-MyoA motor complex is important but not essential for gliding motility and host cell invasion. PLoS One 9:e91819. https://doi.org/10.1371/ journal.pone.0091819 
Foth BJ, Goedecke MC, Soldati D (2006) New insights into myosin evolution and classification. Proc Natl Acad Sci 103:3681-3686. https://doi.org/10.1073/ pnas.0506307103

Francia ME, Striepen B (2014) Cell division in apicomplexan parasites. Nat Rev Microbiol 12:125-136. https://doi.org/10.1038/nrmicro3184

Frénal K, Polonais V, Marq J-B et al (2010) Functional dissection of the apicomplexan glideosome molecular architecture. Cell Host Microbe 8:343-357. https:// doi.org/10.1016/j.chom.2010.09.002

Frénal K, Marq J-B, Jacot D et al (2014) Plasticity between MyoC- and MyoA-glideosomes: an example of functional compensation in Toxoplasma gondii invasion. PLoS Pathog 10:e1004504. https://doi.org/10.1371/ journal.ppat.1004504

Frénal K, Dubremetz J-F, Lebrun M, Soldati-Favre D (2017a) Gliding motility powers invasion and egress in Apicomplexa. Nat Rev Microbiol 15:645-660. https://doi.org/10.1038/nrmicro.2017.86

Frénal K, Jacot D, Hammoudi P-M et al (2017b) Myosindependent cell-cell communication controls synchronicity of division in acute and chronic stages of Toxoplasma gondii. Nat Commun 8:15710. https:// doi.org/10.1038/ncomms 15710

Gaji RY, Johnson DE, Treeck M et al (2015) Phosphorylation of a myosin motor by TgCDPK3 facilitates rapid initiation of motility during Toxoplasma gondii egress. PLoS Pathog 11:e1005268. https://doi.org/10.1371/journal.ppat.1005268

Ganter M, Schüler H, Matuschewski K (2009) Vital role for the Plasmodium actin capping protein (CP) beta-subunit in motility of malaria sporozoites. Mol Microbiol 74:1356-1367. https://doi. org/10.1111/j.1365-2958.2009.06828.x

Ganter M, Rizopoulos Z, Schüler H, Matuschewski K (2015) Pivotal and distinct role for Plasmodium actin capping protein alpha during blood infection of the malaria parasite. Mol Microbiol 96:84-94. https://doi. org/10.1111/mmi.12922

Garg S, Agarwal S, Kumar S et al (2013) Calciumdependent permeabilization of erythrocytes by a perforin-like protein during egress of malaria parasites. Nat Commun 4:1736. https://doi.org/10.1038/ ncomms 2725

Gordon JL, Sibley LD (2005) Comparative genome analysis reveals a conserved family of actin-like proteins in apicomplexan parasites. BMC Genomics 6:179. https://doi.org/10.1186/1471-2164-6-179

Gould SB, Tham W-H, Cowman AF et al (2008) Alveolins, a new family of cortical proteins that define the protist infrakingdom Alveolata. Mol Biol Evol 25:12191230. https://doi.org/10.1093/molbev/msn070

Graindorge A, Frénal K, Jacot D et al (2016) The conoid associated motor $\mathrm{MyoH}$ is indispensable for Toxoplasma gondii entry and exit from host cells. PLoS Pathog 12:e1005388. https://doi.org/10.1371/ journal.ppat.1005388

Green JL, Martin SR, Fielden J et al (2006) The MTIPmyosin A complex in blood stage malaria parasites.
J Mol Biol 355:933-941. https://doi.org/10.1016/j. jmb.2005.11.027

Green JL, Wall RJ, Vahokoski J et al (2017) Compositional and expression analyses of the glideosome during the Plasmodium life cycle reveal an additional myosin light chain required for maximum motility. J Biol Chem 292:17857-17875. https://doi.org/10.1074/jbc. M117.802769

Hakimi M-A, Olias P, Sibley LD (2017) Toxoplasma effectors targeting host signaling and transcription. Clin Microbiol Rev 30:615-645. https://doi. org/10.1128/CMR.00005-17

Hammer JA, Sellers JR (2012) Walking to work: roles for class $\mathrm{V}$ myosins as cargo transporters. Nat Rev Mol Cell Biol 13:13-26. https://doi.org/10.1038/nrm3248

Harding CR, Meissner M (2014) The inner membrane complex through development of Toxoplasma gondii and Plasmodium. Cell Microbiol 16:632-641. https:// doi.org/10.1111/cmi.12285

Harvey KL, Yap A, Gilson PR et al (2014) Insights and controversies into the role of the key apicomplexan invasion ligand, apical membrane antigen 1. Int J Parasitol 44:853-857. https://doi.org/10.1016/j. ijpara.2014.08.001

Heaslip AT, Nelson SR, Warshaw DM (2016) Dense granule trafficking in Toxoplasma gondii requires a unique class 27 myosin and actin filaments. Mol Biol Cell 27:2080-2089. https://doi.org/10.1091/mbc. E15-12-0824

Heintzelman MB, Schwartzman JD (1997) A novel class of unconventional myosins from Toxoplasma gondii. J Mol Biol 271:139-146. https://doi.org/10.1006/ jmbi.1997.1167

Herm-Götz A, Weiss S, Stratmann R et al (2002) Toxoplasma gondii myosin A and its light chain: a fast, single-headed, plus-end-directed motor. EMBO J 21:2149-2158. https://doi.org/10.1093/ emboj/21.9.2149

Herm-Götz A, Delbac F, Weiss S et al (2006) Functional and biophysical analyses of the class XIV Toxoplasma gondii myosin D. J Muscle Res Cell Motil 27:139151. https://doi.org/10.1007/s10974-005-9046-1

Hettmann C, Herm A, Geiter A et al (2000) A dibasic motif in the tail of a class XIV apicomplexan myo$\sin$ is an essential determinant of plasma membrane localization. Mol Biol Cell 11:1385-1400. https://doi. org/10.1091/mbc.11.4.1385

Hliscs M, Sattler JM, Tempel W et al (2010) Structure and function of a $\mathrm{G}$-actin sequestering protein with a vital role in malaria oocyst development inside the mosquito vector. J Biol Chem 285:11572-11583. https:// doi.org/10.1074/jbc.M109.054916

Hliscs M, Millet C, Dixon MW et al (2015) Organization and function of an actin cytoskeleton in Plasmodium falciparum gametocytes. Cell Microbiol 17:207-225. https://doi.org/10.1111/cmi.12359

$\mathrm{Hu}$ K (2008) Organizational changes of the daughter basal complex during the parasite replication of Toxoplasma gondii. PLoS Pathog 4:e10. https://doi.org/10.1371/ journal.ppat.0040010 
Hu K, Roos DS, Murray JM (2002) A novel polymer of tubulin forms the conoid of Toxoplasma gondii. $\mathrm{J}$ Cell Biol 156:1039-1050. https://doi.org/10.1083/ jcb.200112086

Hu K, Johnson J, Florens L et al (2006) Cytoskeletal components of an invasion machine - the apical complex of Toxoplasma gondii. PLoS Pathog 2:e13. https://doi. org/10.1371/journal.ppat.0020013

Hunt A, Russell MRG, Wagener J et al (2019, October 2) Differential requirements for cyclase-associated protein (CAP) in actin-dependent processes of Toxoplasma gondii. Elife 8:pii: e50598. https://doi. org/10.7554/eLife.50598.001

Jacot D, Daher W, Soldati-Favre D (2013) Toxoplasma gondii myosin $\mathrm{F}$, an essential motor for centrosomes positioning and apicoplast inheritance. EMBO J 32:1702-1716. https://doi.org/10.1038/ emboj.2013.113

Jacot D, Frénal K, Marq J-B et al (2014) Assessment of phosphorylation in Toxoplasma glideosome assembly and function. Cell Microbiol 16:1518-1532. https:// doi.org/10.1111/cmi.12307

Jacot D, Tosetti N, Pires I et al (2016) An Apicomplexan actin-binding protein serves as a connector and lipid sensor to coordinate motility and invasion. Cell Host Microbe 20:731-743. https://doi.org/10.1016/j. chom.2016.10.020

Kadirvel P, Anishetty S (2018) Potential role of saltbridges in the hinge-like movement of apicomplexa specific $\beta$-hairpin of Plasmodium and Toxoplasma profilins: a molecular dynamics simulation study. J Cell Biochem 119:3683-3696. https://doi.org/10.1002/ jcb. 26579

Kafsack BFC, Pena JDO, Coppens I et al (2009) Rapid membrane disruption by a perforin-like protein facilitates parasite exit from host cells. Science 323:530533. https://doi.org/10.1126/science. 1165740

Kucera K, Koblansky AA, Saunders LP et al (2010) Structure-based analysis of Toxoplasma gondii profilin: a parasite-specific motif is required for recognition by toll-like receptor 11. J Mol Biol 403:616-629. https://doi.org/10.1016/j.jmb.2010.09.022

Kumpula E-P, Pires I, Lasiwa D et al (2017) Apicomplexan actin polymerization depends on nucleation. Sci Rep 7:12137. https://doi.org/10.1038/ s41598-017-11330-w

Kumpula E-P, Lopez AJ, Tajedin L et al (2019) Atomic view into Plasmodium actin polymerization, ATP hydrolysis, and fragmentation. PLoS Biol 17:e3000315. https://doi.org/10.1371/journal. pbio. 3000315

Kursula I, Kursula P, Ganter M et al (2008) Structural basis for parasite-specific functions of the divergent profilin of Plasmodium falciparum. Structure 16:1638-1648. https://doi.org/10.1016/j.str.2008.09.008

Lentini G, Dubois DJ, Maco B et al (2019) The roles of CEN2 and DLC8a in apical secretory organelles discharge of Toxoplasma gondii. Traffic 20:583-600. https://doi.org/10.1111/tra.12673
Letunic I, Bork P (2018) 20 years of the SMART protein domain annotation resource. Nucleic Acids Res 46(D1)D493-D496. https://doi.org/10.1093/nar/ gkx922

Long S, Brown KM, Drewry LL et al (2017) Calmodulinlike proteins localized to the conoid regulate motility and cell invasion by Toxoplasma gondii. PLoS Pathog 13:e1006379. https://doi.org/10.1371/journal. ppat. 1006379

Makkonen M, Bertling E, Chebotareva NA et al (2013) Mammalian and malaria parasite cyclase-associated proteins catalyze nucleotide exchange on G-actin through a conserved mechanism. J Biol Chem 288:984994. https://doi.org/10.1074/jbc.M112.435719

Mehta S, Sibley LD (2010) Toxoplasma gondii actin depolymerizing factor acts primarily to sequester G-actin. J Biol Chem 285:6835-6847. https://doi.org/10.1074/ jbc.M109.068155

Mehta S, Sibley LD (2011) Actin depolymerizing factor controls actin turnover and gliding motility in Toxoplasma gondii. Mol Biol Cell 22:1290-1299. https://doi.org/10.1091/mbc.E10-12-0939

Meissner M, Schlüter D, Soldati D (2002) Role of Toxoplasma gondii myosin A in powering parasite gliding and host cell invasion. Science 298:837-840. https://doi.org/10.1126/science.1074553

Mercier C, Cesbron-Delauw M-F (2015) Toxoplasma secretory granules: one population or more? Trends Parasitol 31:60-71. https://doi.org/10.1016/j. pt.2014.12.002

Millholland MG, Chandramohanadas R, Pizzarro A et al (2011) The malaria parasite progressively dismantles the host erythrocyte cytoskeleton for efficient egress. Mol Cell Proteomics 10:M111.010678. https://doi. org/10.1074/mcp.M111.010678

Monteiro VG, de Melo EJ, Attias M, de Souza W (2001) Morphological changes during conoid extrusion in Toxoplasma gondii tachyzoites treated with calcium ionophore. J Struct Biol 136:181-189. https://doi. org/10.1006/jsbi.2002.4444

Mordue DG, Håkansson S, Niesman I, Sibley LD (1999) Toxoplasma gondii resides in a vacuole that avoids fusion with host cell endocytic and exocytic vesicular trafficking pathways. Exp Parasitol 92:87-99

Moreau CA, Bhargav SP, Kumar H et al (2017) A unique profilin-actin interface is important for malaria parasite motility. PLoS Pathog 13:e1006412. https:// doi.org/10.1371/journal.ppat.1006412

Mueller C, Klages N, Jacot D et al (2013) The Toxoplasma protein ARO mediates the apical positioning of rhoptry organelles, a prerequisite for host cell invasion. Cell Host Microbe 13:289-301. https://doi.org/10.1016/j. chom.2013.02.001

Mueller C, Graindorge A, Soldati-Favre D (2017) Functions of myosin motors tailored for parasitism. Curr Opin Microbiol 40:113-122. https://doi. org/10.1016/j.mib.2017.11.003

Nebl T, Prieto JH, Kapp E et al (2011) Quantitative in vivo analyses reveal calcium-dependent phos- 
phorylation sites and identifies a novel component of the toxoplasma invasion motor complex. PLoS Pathog 7:e1002222. https://doi.org/10.1371/journal. ppat. 1002222

Nishi M, Hu K, Murray JM, Roos DS (2008) Organellar dynamics during the cell cycle of Toxoplasma gondii. J Cell Sci 121:1559-1568. https://doi.org/10.1242/ jes.021089

Odronitz F, Kollmar M (2007) Drawing the tree of eukaryotic life based on the analysis of 2,269 manually annotated myosins from 328 species. Genome Biol 8:R196. https://doi.org/10.1186/gb-2007-8-9-r196

Olshina MA, Angrisano F, Marapana DS et al (2015) Plasmodium falciparum coronin organizes arrays of parallel actin filaments potentially guiding directional motility in invasive malaria parasites. Malar J 14:280. https://doi.org/10.1186/s12936-015-0801-5

Pavlou G, Biesaga M, Touquet B et al (2018) Toxoplasma parasite twisting motion mechanically induces host cell membrane fission to complete invasion within a protective vacuole. Cell Host Microbe 24:81-96.e5. https://doi.org/10.1016/j.chom.2018.06.003

Periz J, Whitelaw J, Harding C et al (2017) Toxoplasma gondii $\mathrm{F}$-actin forms an extensive filamentous network required for material exchange and parasite maturation. Elife 6:pii: e24119. https://doi.org/10.7554/ eLife. 24119

Plattner F, Yarovinsky F, Romero S et al (2008) Toxoplasma profilin is essential for host cell invasion and TLR11-dependent induction of an interleukin-12 response. Cell Host Microbe 3:77-87. https://doi. org/10.1016/j.chom.2008.01.001

Pollard TD (2016) Actin and actin-binding proteins. Cold Spring Harb Perspect Biol 8. https://doi.org/10.1101/ cshperspect.a018226

Polonais V, Javier Foth B, Chinthalapudi K et al (2011) Unusual anchor of a motor complex (MyoD-MLC2) to the plasma membrane of Toxoplasma gondii. Traffic 12:287-300. https://doi. org/10.1111/j.1600-0854.2010.01148.x

Pospich S, Kumpula E-P, von der Ecken J et al (2017) Nearatomic structure of jasplakinolide-stabilized malaria parasite F-actin reveals the structural basis of filament instability. Proc Natl Acad Sci U S A 114:1063610641. https://doi.org/10.1073/pnas.1707506114

Powell CJ, Jenkins ML, Parker ML et al (2017) Dissecting the molecular assembly of the Toxoplasma gondii MyoA motility complex. J Biol Chem 292:1946919477. https://doi.org/10.1074/jbc.M117.809632

Powell CJ, Ramaswamy R, Kelsen A et al (2018) Structural and mechanistic insights into the function of the unconventional class XIV myosin MyoA from Toxoplasma gondii. Proc Natl Acad Sci U S A 115:E10548-E10555. https://doi.org/10.1073/ pnas. 1811167115

Richards TA, Cavalier-Smith T (2005) Myosin domain evolution and the primary divergence of eukaryotes. Nature 436:1113-1118. https://doi.org/10.1038/ nature 03949
Rudlaff RM, Kraemer S, Streva VA, Dvorin JD (2019) An essential contractile ring protein controls cell division in Plasmodium falciparum. Nat Commun 10:2181. https://doi.org/10.1038/s41467-019-10214-z

Sahoo N, Beatty W, Heuser J et al (2005) Unusual kinetic and structural properties control rapid assembly and turnover of actin in the parasite Toxoplasma gondii. MBoC 17:895-906. https://doi.org/10.1091/mbc. e05-06-0512

Salamun J, Kallio JP, Daher W et al (2014) Structure of Toxoplasma gondii coronin, an actin-binding protein that relocalizes to the posterior pole of invasive parasites and contributes to invasion and egress. FASEB J 28:4729-4747. https://doi.org/10.1096/ fj.14-252569

Schmitz S, Grainger M, Howell S et al (2005) Malaria parasite actin filaments are very short. J Mol Biol 349:113125. https://doi.org/10.1016/j.jmb.2005.03.056

Schüler H, Matuschewski K (2006) Regulation of apicomplexan microfilament dynamics by a minimal set of actin-binding proteins. Traffic 7:1433-1439. https:// doi.org/10.1111/j.1600-0854.2006.00484.x

Schüler H, Mueller A-K, Matuschewski K (2005a) Unusual properties of Plasmodium falciparum actin: new insights into microfilament dynamics of apicomplexan parasites. FEBS Lett 579:655-660. https://doi. org/10.1016/j.febslet.2004.12.037

Schüler H, Mueller A-K, Matuschewski K (2005b) A Plasmodium actin-depolymerizing factor that binds exclusively to actin monomers. MBoC 16:4013-4023. https://doi.org/10.1091/mbc.e05-02-0086

Sebastian S, Brochet M, Collins MO et al (2012) A Plasmodium calcium-dependent protein kinase controls zygote development and transmission by translationally activating repressed mRNAs. Cell Host Microbe 12:9-19. https://doi.org/10.1016/j. chom.2012.05.014

Sebé-Pedrós A, Grau-Bové X, Richards TA, Ruiz-Trillo I (2014) Evolution and classification of myosins, a paneukaryotic whole-genome approach. Genome Biol Evol 6:290-305. https://doi.org/10.1093/gbe/evu013

Siden-Kiamos I, Ganter M, Kunze A et al (2011) Stage-specific depletion of myosin a supports an essential role in motility of malarial ookinetes. Cell Microbiol 13:1996-2006. https://doi. org/10.1111/j.1462-5822.2011.01686.x

Siden-Kiamos I, Louis C, Matuschewski K (2012) Evidence for filamentous actin in ookinetes of a malarial parasite. Mol Biochem Parasitol 181:186-189. https://doi.org/10.1016/j.molbiopara.2011.11.002

Sidik SM, Huet D, Ganesan SM et al (2016) A genomewide CRISPR screen in Toxoplasma identifies essential Apicomplexan genes. Cell 166:1423-1435.e12. https://doi.org/10.1016/j.cell.2016.08.019

Singh BK, Sattler JM, Chatterjee M et al (2011) Crystal structures explain functional differences in the two actin depolymerization factors of the malaria parasite. J Biol Chem 286:28256-28264. https://doi. org/10.1074/jbc.M111.211730 
Skillman KM, Diraviyam K, Khan A et al (2011) Evolutionarily divergent, unstable filamentous actin is essential for gliding motility in Apicomplexan parasites. PLoS Pathog 7:e1002280. https://doi. org/10.1371/journal.ppat.1002280

Skillman KM, Daher W, Ma CI et al (2012) Toxoplasma gondii profilin acts primarily to sequester G-actin while formins efficiently nucleate actin filament formation in Vitro. Biochemistry 51:2486-2495. https:// doi.org/10.1021/bi201704y

Skillman KM, Ma CI, Fremont DH et al (2013) The unusual dynamics of parasite actin result from isodesmic polymerization. Nat Commun 4:2285. https://doi. org/10.1038/ncomms3285

Stortz JF, Del Rosario M, Singer M et al (2018) Formin-2 drives polymerisation of actin filaments enabling segregation of apicoplasts and cytokinesis in Plasmodium falciparum. Elife. 2019 Jul 19;8. pii: e49030. https:// doi.org/10.7554/eLife.49030.005

Striepen B, Crawford MJ, Shaw MK et al (2000) The plastid of Toxoplasma gondii is divided by association with the centrosomes. J Cell Biol 151:1423-1434. https://doi.org/10.1083/jcb.151.7.1423

Tosetti N, Dos Santos Pacheco N, Soldati-Favre D, Jacot D (2019) Three F-actin assembly centers regulate organelle inheritance, cell-cell communication and motility in Toxoplasma gondii. Elife 8:pii: e42669. https://doi.org/10.7554/eLife.42669
Vahokoski J, Bhargav SP, Desfosses A et al (2014) Structural differences explain diverse functions of Plasmodium actins. PLoS Pathog 10:e1004091. https://doi.org/10.1371/journal.ppat.1004091

van Dooren GG, Striepen B (2013) The algal past and parasite present of the apicoplast. Annu Rev Microbiol 67:271-289. https://doi.org/10.1146/ annurev-micro-092412-155741

Wall RJ, Zeeshan M, Katris NJ et al (2019) Systematic analysis of Plasmodium myosins reveals differential expression, localization and function in invasive and proliferative parasite stages. Cell Microbiol 21(10):e13082

Williams MJ, Alonso H, Enciso M et al (2015) Two essential light chains regulate the MyoA lever arm to promote toxoplasma gliding motility. MBio 6:e0845-e00815. https://doi.org/10.1128/ mBio.00845-15

Yadav R, Pathak PP, Shukla VK et al (2011) Solution structure and dynamics of ADF from Toxoplasma gondii. J Struct Biol 176:97-111. https://doi.org/10.1016/j. jsb.2011.07.011

Yusuf NA, Green JL, Wall RJ et al (2015) The Plasmodium class XIV myosin, MyoB, has a distinct subcellular location in invasive and motile stages of the malaria parasite and an unusual light chain. J Biol Chem 290:12147-12164. https://doi.org/10.1074/jbc. M115.637694 